\title{
Role of Powder Particle Size on Laser Powder Bed Fusion Processability of AlSi10Mg Alloy
}

\author{
M.A. Balbaa ${ }^{1 *}$, A. Ghasemi ${ }^{1}$, E. Fereiduni ${ }^{1}$, M.A. Elbestawi ${ }^{1 *}$, S.D. Jadhav ${ }^{2}$, J-P Kruth $^{3}$ \\ ${ }^{1}$ Department of Mechanical Engineering, McMaster University, Hamilton, ON, Canada \\ ${ }^{2}$ Department of Materials Engineering, KU Leuven, Kasteelpark Arenberg 44, B-3001, Heverlee, Belgium \\ ${ }^{3}$ PMA, Department of Mechanical Engineering, KU Leuven \& Member of Flanders Make, Celestijnenlaan 300, B- \\ 3001, Heverlee, Belgium \\ * Corresponding authors: M.A. Balbaa (ㅁalbaam@mcmaster.ca) and M.A. Elbestawi (elbestaw@mcmaster.ca)
}

\begin{abstract}
Laser powder bed fusion (L-PBF) is one of the most promising additive manufacturing (AM) methods which provides an exceptional opportunity to improve the existing designs and move toward fabricating fine features and complex geometries with higher efficiencies. Considering the layer-wise nature of this technique, the possibility of fabricating fine features is tied to the ability to deposit thin powder layers in this process. Since the powder layer thickness is directly dictated by the powder particle size, finer powders are required to further enhance the ability of the L-PBF technique in manufacturing fine features and intricate geometries. Accordingly, this study aims at investigating the processability of fine $\mathrm{AlSi} 10 \mathrm{Mg}$ powder $(\mathrm{D} 50=9 \mu \mathrm{m})$ by using the L-PBF process. The densification level, surface quality and dimensional accuracy of the final parts are investigated in a wide range of process parameters and are compared to those manufactured by the commonly used AlSi10Mg powder (referred to as coarse powder with D50 $=40 \mu \mathrm{m}$ ). The underlying reasons behind the different processability of fine and coarse powders are explored from the density, surface quality, microhardness and dimensional accuracy viewpoints through analyzing the flowability, bed packing density and optical absorption of powders. Moreover, the process-microstructuremicrohardness relationship is assessed in detail for both fine and coarse powders. This study reinforces the idea that the utilization of fine powders in the range used in this study for L-PBF processing is rather challenging.
\end{abstract}

Keywords: Laser powder bed fusion (L-PBF); Particle size; Density; Laser absorptivity; Dimensional accuracy; Surface roughness 


\section{Introduction}

In recent years, the increase in the power level in many electronic applications has made the thermal management of the systems rather challenging, especially in microelectronic devices and miniaturized personal computers $[1,2]$. Insufficient heat transfer of the excessive heat generated during the operation of these devices adversely affects their performance and may result in thermal failure [2]. To mitigate this concern, advanced manufacturing methods are required to produce more complicated architectures (e.g., lattice structures), which can increase the effective surface area of the heat exchangers by providing more channels for transportation of the coolant inside their volume [3-5]. In light of this scenario, additive manufacturing (AM) is the best choice for near-net-shape fabrication of these complex 3D components [6, 7]. Laser powder bed fusion (L-PBF) process is one of the most promising AM techniques in terms of fabricating fine features that are required in tube/fin, plate/fin, finless tube micro-channels, pitot tube and twisted tube heat exchangers [5]. Fabrication of these heat exchangers through the L-PBF process was reported to be successful using aluminum (Al) alloys, including AlSi10Mg and AlSi12, among others [8, 9]. However, there is still a great interest in decreasing the minimum achievable feature size in these devices to move towards more complicated designs having finer features and higher efficiencies.

In the L-PBF process, a focused laser beam directly creates a 3D part in a layer-wise manner based on a computer-aided design (CAD) model by selectively fusing regions of a powder bed [10-14]. For a given material (e.g., AlSi10Mg), the finest achievable feature is dictated by the laser beam diameter and the powder layer thickness. Laser spot sizes less than $40 \mu \mathrm{m}$ are not common in the L-PBF process due to the limitations with the currently existing machines. However, there seems to be no limitation in decreasing the powder layer thickness since it is a function of the powder particle size [15, 16]. For instance, for $\mathrm{Al}$ alloy powders with particles in the range of $15-50 \mu \mathrm{m}$, powder layer thicknesses less than $30 \mu \mathrm{m}$ cannot be obtained. Nevertheless, finer micro-scale powder particles in the range of 1-20 $\mu \mathrm{m}$ and even submicron powders are also commercially available to further decrease the powder layer thickness and possibly provide the chance of printing finer features. Applying fine powder particles (less than $20 \mu \mathrm{m}$ ) in the L$\mathrm{PBF}$ process seems to be beneficial not only in terms of fabricating finer features but also from the $\mathrm{Al}$ printability viewpoint. For example, the presence of fine powder particles enhances the consolidation kinetics due to the lower amount of heat required to melt the powder particles [17]. Moreover, the decrease in the powder particle size results in a higher specific surface area relative to volume, which in turn enhances the laser absorptivity $[17,18]$. Due to the high laser reflectivity of Al-based alloys, the enhancement of their laser absorptivity is of utmost importance in L-PBF processing [19]. It has to be noted that $\mathrm{Al}$ is on the Special Health Hazard Substance List due to its flammability and high affinity to oxidation in the powder form (particle sizes less than $420 \mu \mathrm{m}$ ). Fine powders should be treated with more caution since they have 
lower minimum ignition energy as per standard ASTM E2019. For instance, by decreasing the mean particle size of $\mathrm{Al}$ powder from 32 to $9 \mu \mathrm{m}$, the minimum ignition energy declines from 10 to $4 \mathrm{~mJ}[20,21]$.

Although the influence of process parameters and the scanning strategy on the quality of L-PBF processed $\mathrm{Al}$ alloys parts has been well investigated and documented in the literature [19, 22-26], this question has still remained unanswered that whether or not it is possible to fabricate sound Al-based parts with finer features using finer powder feedstocks.

Table 1 summarizes the research studies that have been conducted to analyze the effect of particle size on powder characteristics and/or quality of the final printed parts. Referring to Table 1, the following vacancies need to be fulfilled:

- Flowability: With a few exceptions [27], the literature appears to be devoid of investigating the role of the powder particle size on the powder flowability, which is of great importance in the L-PBF process. It is worth to mention that even when the flowability was concerned, the Hall flowmeter was utilized to measure the flowability. Although the Hall flowmeter is known to be closer to the AM process (especially the powder fed techniques) than other conventional powder flowability measurement techniques, it has major limitations with evaluating the flowability of cohesive powders which are still good enough for powder bed fusion additive manufacturing (PBF-AM) processes [28]. Among various techniques currently available for the powder flowability measurement, the FT4 Freeman powder rheometer technique has been recommended since the interaction of the precision blade with the powder resembles that of the recoater/powder in the LPBF process [29].

- Absorptivity: The influence of the powder particle size on the laser absorptivity has not been reported through experimental measurements to the best knowledge of authors. By providing a larger specific surface area relative to volume for powder/laser interactions, finer powder particles are expected to have higher absorptivity and, therefore, higher kinetics of densification [17].

- Printing samples: Although powder characterization provides valuable information about the printability potential of fine powder particles, the literature lacks a systematic study correlating the powder behaviors (flowability, packing density and absorptivity) to the densification level, surface quality, dimensional accuracy, microstructure and mechanical properties of the final parts. 
Table 1. Effect of powder particle size on the powder characteristics and/or the quality of the final printed parts in the literature.

\begin{tabular}{|c|c|c|c|}
\hline System & $\begin{array}{c}\text { Powder particle size } \\
\qquad(\mu \mathrm{m})\end{array}$ & Research focus & Reference \\
\hline $\begin{array}{l}\text { Ni-base } \\
\text { alloy }\end{array}$ & $\begin{array}{c}150-200 \\
100-150 \\
50-75 \\
25-40 \\
<20\end{array}$ & $\begin{array}{l}\text { Influence of powder particle size, and different coarse-to-fine } \\
\text { powder ratios on the powder bed density by depositing a } 500 \\
\mu \mathrm{m} \text { thick powder layer using a metallic ruler as the recoater. }\end{array}$ & [30] \\
\hline SS316L & $\begin{aligned} \mathrm{D}_{50}= & 15.05 \\
& 28.19 \\
& 37\end{aligned}$ & $\begin{array}{l}\text { Effect of powder particle size on the relative powder density, } \\
\text { effective powder layer thickness and the density of the L-PBF } \\
\text { fabricated parts. }\end{array}$ & [31] \\
\hline SS316L & $\begin{array}{r}\mathrm{D}_{50}=15.12 \\
28.26 \\
37.70\end{array}$ & $\begin{array}{l}\text { Comparison between the density, surface quality and } \\
\text { mechanical properties of parts fabricated by the L-PBF process } \\
\text { using different powder sizes and size distributions. }\end{array}$ & {$[32]$} \\
\hline IN718 & $\begin{aligned} & \mathrm{D}_{\mathrm{ave}}= 7 \\
& 21 \\
& 70\end{aligned}$ & Influence of powder size on the powder bed packing density. & {$[33]$} \\
\hline AlSi7Mg & $\begin{array}{r}\mathrm{D}_{50}=31 \\
63 \\
70\end{array}$ & $\begin{array}{l}\text { Powders with different sizes were characterized in terms of } \\
\text { flowability, powder bed packing density, particle segregation } \\
\text { during recoating and particle cohesiveness. }\end{array}$ & [27] \\
\hline $\mathbf{F e}$ & $\begin{array}{r}\mathrm{D}_{50}=10 \\
26 \\
41 \\
51 \\
68 \\
104 \\
171\end{array}$ & $\begin{array}{l}\text { The role of particle size on the microstructure of the printed } \\
\text { parts (level of defects), surface morphology and particle } \\
\text { bonding mechanism. }\end{array}$ & {$[17]$} \\
\hline $\mathbf{T i}$ & $\begin{array}{c}45-106 \\
75-106 \\
45-75\end{array}$ & $\begin{array}{l}\text { Influence of powder particle size on the flowability, apparent } \\
\text { and tap density and the powder bed macro-surface profile. }\end{array}$ & {$[34]$} \\
\hline
\end{tabular}

This study discusses the possibility of fabricating sound parts using fine powder particles (less than $20 \mu \mathrm{m}$ ). AlSi10Mg powders with two different sizes (coarse: 15-70 $\mu \mathrm{m}$ and fine: 1-20 $\mu \mathrm{m}$ ) were employed as a model to recognize the effect of the particle size on the quality of final parts in terms of density (level of defects), surface quality, dimensional accuracy, microstructure and microhardness. The fundamental reasons behind the formation of defects, as well as the surface roughness trends and deviation from the nominal dimensions, were explored based on four key factors, namely, process parameters, powder flowability, powder bed packing density and powder laser absorptivity. In addition, the influence of powder particle size on the final microstructure was discussed in detail. To consider the physical properties of the material along with the process parameters in the energy density calculations, a modified volumetric energy density was proposed, considering the laser absorptivity and effective powder layer thickness of the powder 
feedstock. The lessons learned from this study can answer the question regarding the ability of fine powder particles to produce sound parts with finer features.

\section{Materials and Experimental Procedure}

\subsection{Powder characteristics (chemical composition, particle size distribution and morphology)}

The powders used in this study were fine and coarse AlSi10Mg alloy with the nominal chemical compositions provided in Table 2. The particle size distribution (PSD) of both fine and coarse powders was investigated by means of laser diffraction according to the ASTM B822-17 standard [35]. Figure 1 presents the particle size distribution (PSD) of coarse and fine AlSi10Mg powders. The D10, D50, and D90 of powders representing the particle diameters at 10,50 and $90 \%$ in the cumulative distribution are also provided in Figure 1. As seen, the powders follow a Gaussian distribution with the mean particle size (D50) being $\sim 9$ and $\sim 40 \mu \mathrm{m}$ for fine and coarse powders, respectively.

Table 2. Nominal chemical composition of powders.

\begin{tabular}{ccccccc}
\hline \multirow{2}{*}{ Powder } & \multicolumn{7}{c}{ Elements (wt. \%) } \\
\cline { 2 - 7 } & $\mathrm{Al}$ & $\mathrm{Si}$ & $\mathrm{Mg}$ & $\mathrm{Fe}$ & $\mathrm{Cu}$ & Other \\
\hline Coarse AlSi10Mg & Bal. & 9.76 & 0.21 & 0.07 & 0.08 & 1.5 \\
\hline Fine AlSi10Mg & Bal. & 8.56 & 0.23 & 0.19 & 0.04 & 1.29 \\
\hline
\end{tabular}

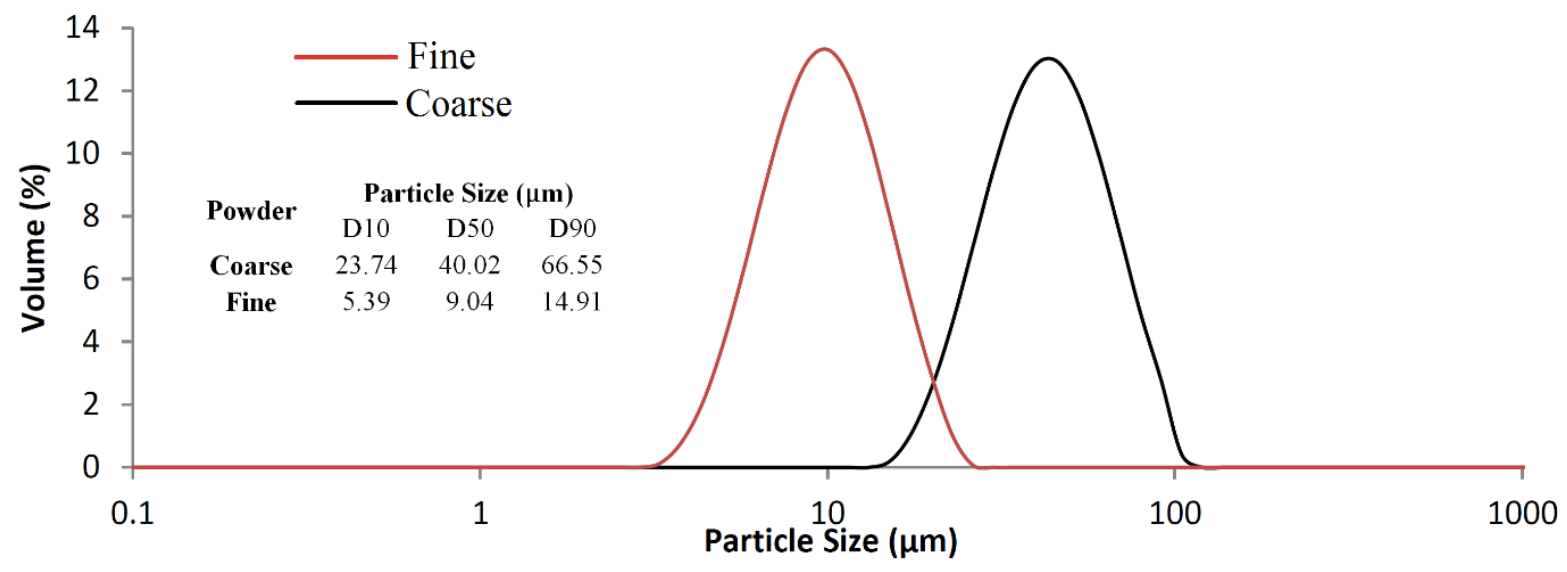

Figure 1. Particle size distribution (PSD) of coarse and fine AlSilOMg powders used in this study.

The morphology of powders was observed using a Vega Tescan scanning electron microscopy (SEM) with an accelerating voltage of $20 \mathrm{kV}$. The SEM was equipped with an energy dispersive X-ray spectroscopy (EDS) detector for elemental analysis. Figure 2 shows the SEM micrographs of the gas atomized AlSi10Mg powders. As shown in Figure 2(a), a vast majority of particles in the coarse powder are almost spherical/quasi-spherical in shape. However, this powder contains particles which show some degrees of deviation from spherical to elongated shape (Figure 2(a) and (b)). Close observation of powder particles 
also reveals the presence of satellites on the surface of almost all particles (Figure 2(b)). These satellites are believed to form when the faster-solidified finer particles adhere to the molten or semi-solid surface of the coarser particles due to the in-flight collisions existing among the particles during the gas atomization process [36]. Morphological observation of the fine powder indicates that the particles are highly spherical and satellite-free (Figure 2(c) and (d)). This can be attributed to the extremely high cooling rate of fine particles, which provides their full solidification before inter-particle collisions. As can be observed in Figure 2(d), fine powder particles show a high tendency to attach to each other and form agglomerates. However, the particles in the coarse powder do not show signs of agglomeration.
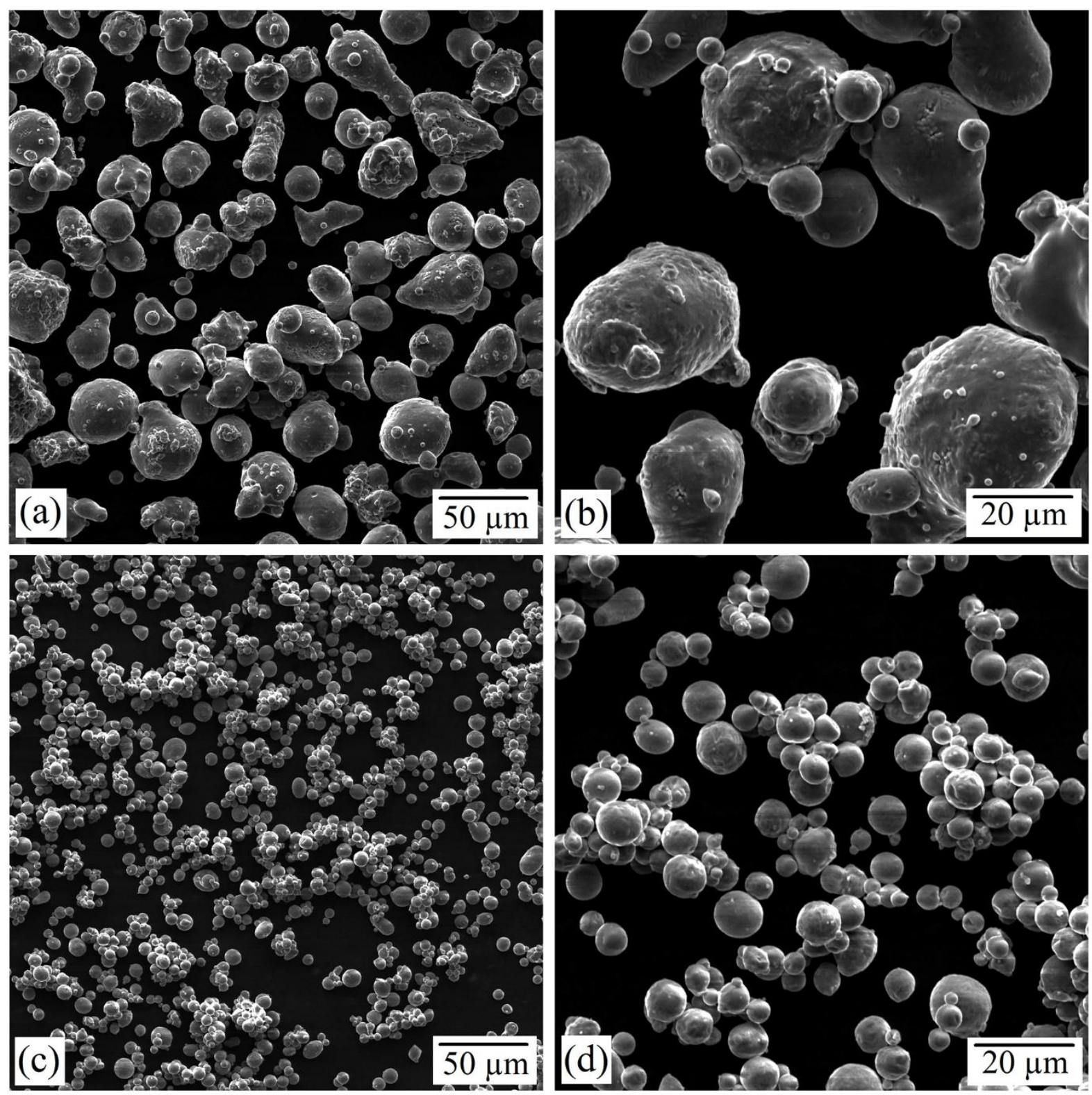

Figure 2. SEM micrographs of: (a) coarse, and (c) fine AlSilOMg powders. (b) and (d) are higher magnification micrographs of the coarse and fine powders shown in (a) and (c), respectively. 


\subsection{Powder behaviors (flowability, packing density and optical absorption)}

The flow behavior of powders was evaluated using three different methods, including Hall and Carney flowmeters (according to the ASTM B213-17 standard [37]) as well as the FT4 Freeman powder rheometer. In the Hall and Carney flowmeter techniques, the powder flowability refers to the time required for $50 \mathrm{~g}$ of powder to flow freely through a standard funnel. The larger diameter of the nozzle in the Carney method makes it possible to evaluate the flowability of powders, which might not flow through the nozzle of the Hall flowmeter. The dynamic flow methodology of the FT4 powder rheometer is of particular relevance to PBF-AM processes, where the powder spreading by the recoater is performed in a dynamic environment under a low-stress state [38]. This test is performed according to the standard "Stable and Variable Flow Rate (SVFR)" method, consisting of stable and variable zones. The stable zone has seven complete test cycles with the same tip speed. Following the stable zone, four complete test cycles with varying blade tip speeds are employed. As shown in Figure 3, each complete test cycle contains downward and then the upward movement of a precision blade in a standard vessel accommodating the powder. The details of the FT4 test procedure and process variables can be found in [29].

The flow behavior of samples was studied by analyzing the basic flow energy (BFE) and specific energy (SE). The BFE represents the ability of the powder to flow under the stressed condition and is defined as the energy required for the rotation of the blade during its downward movement in the $7^{\text {th }}$ test cycle as:

$B F E=E_{\text {test 7,down }}$

Eq. 1

The SE shows the energy required to establish a particular flow pattern in a precise volume of conditioned powder and is defined as the average energy of the upward blade rotation for the $7^{\text {th }}$ and $8^{\text {th }}$ test cycles, divided by the mass of powder remaining in the vessel (Eq. 2). By gently lifting the powder, the upward motion of the blade generates a low stress and unconfined flow mode in the powder.

$S E=\frac{\frac{E_{\text {test } 7, u p}+E_{\text {test } 8, u p}}{2}}{m_{\text {split }}}$

Eq. 2

where $m_{\text {split }}$ is the mass of the powder after the excess powder is removed.

The conditioned bulk density (CBD) of powders was also measured by the FT4 powder rheometer according to the procedure reported in [29]. For each sample, three measurements were performed, and the average value was reported as the CBD based on Eq. 3:

$C B D=m_{\text {split }} / v_{\text {split }}$

Eq. 3

in which $v_{\text {split }}$ signifies the volume of powder after removing the excess powder. The interaction of the precision blade with the powder in the FT4 rheometer resembles that of recoater/powder in PBF-AM processes. In addition, the control over the speed of the blade provided by this technique facilitates analysis of the powder 
flowability for different PBF-AM machines operating with different recoater speeds. Since considering the upward motion of the blade, SE indicates how easily a powder flows in an unconfined or low-stress condition as that of the PBF-AM processes. Due to the dominancy of gravity in the upward movement of the blade, the SE considers the mass of powder in order to compensate the effect of bulk density on the measurements [29]. Although the FT4 Freeman powder rheometer flowability measurement technique has shown to be much more reliable than other traditional techniques, the results obtained by this test cannot be directly related to the ability of a powder to spread during the PBF-AM processes. To date, there is no commercially available powder characterization technique capable of predicting the powder spreadability in PBF-AM processes due to their closed architecture. However, there are a few recent experimental and simulation research studies targeting the powder spreadability measurement and prediction [39-43].

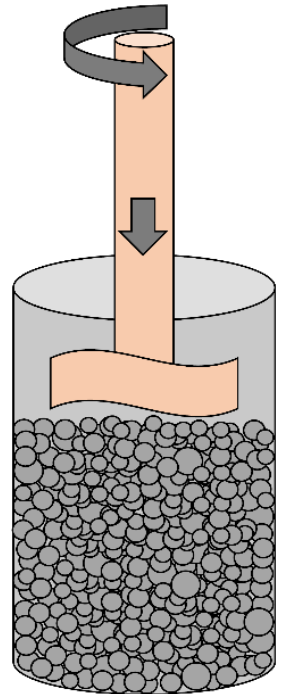

Initial Powder
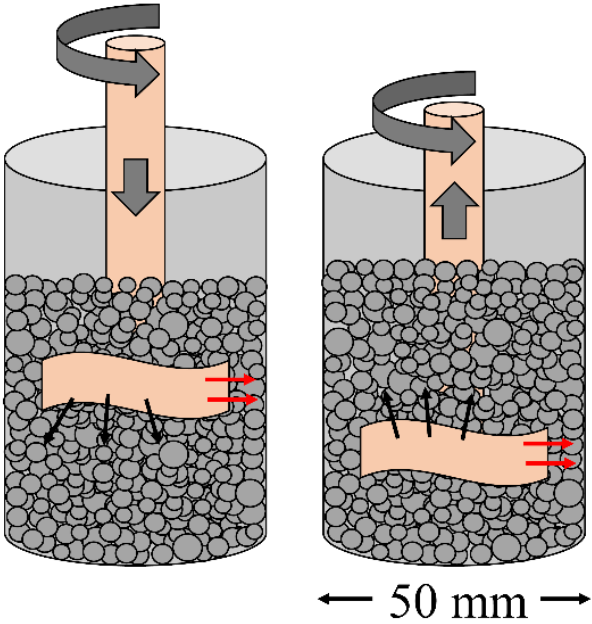
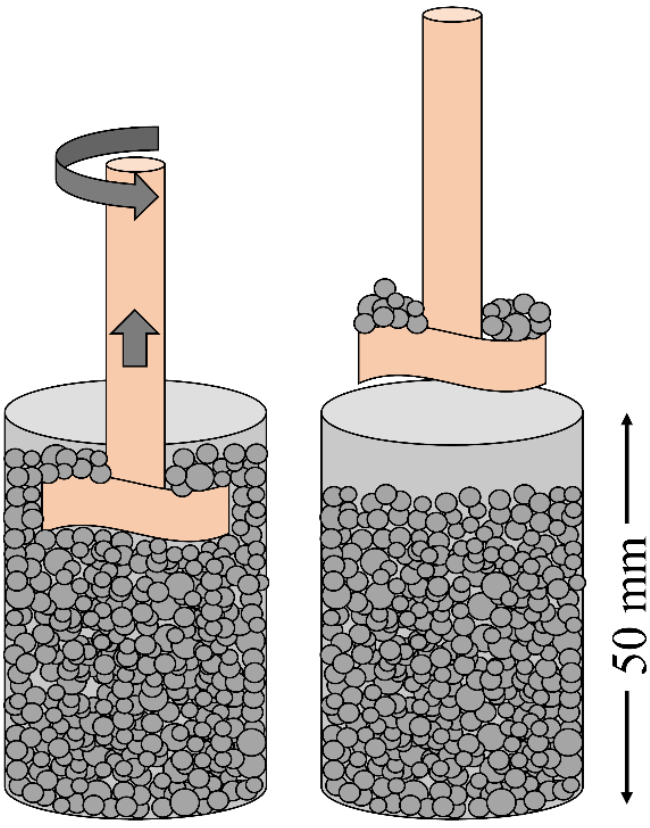

Conditioned Powder

Figure 3. Schematic view of a single test cycle in the dynamic flow methodology of the FT4 Freeman powder rheometer test used to evaluate the powder flowability. The rotating impeller moves downward and then upward through a fixed volume of powder placed in a standard vessel.

The optical absorption of powders was measured by means of diffuse reflectance spectroscopy (DRS) in the wavelength range of 400-1400 $\mathrm{nm}$ using an UV-Visible-NIR LAMBDA 950 Perkin Elmer spectrophotometer equipped with a $150 \mathrm{~mm}$ diameter integrating sphere. The integrating sphere was coated with Spectralon with a spectral resolution of $1 \mathrm{~nm}$. To remove the background and noise, Barium Sulfate powder with a reflectance of $100 \%$ was employed as reference. The powder samples were placed in a quartz cuvette and sealed prior to mounting on a Teflon sample holder for the DRS test. The light sources employed for the measurements had Deuterium (D2) and Tungsten with the wavelength ranges of 200-320 and 320-2500 nm, respectively. The employed detectors were Photon Counting photomultiplier tubes 
(PMT) and Lead Sulfide (PbS), applicable in the wavelength ranges of 200-860.8 and 861-2500 nm, respectively.

\subsection{L-PBF Processing}

The L-PBF machine used in this study was EOS M290 having a $400 \mathrm{~W}$ Yb fiber laser with a focus diameter of $100 \mu \mathrm{m}$. Two sets of samples, each containing 18 cubes with dimensions of $10 \times 10 \times 12 \mathrm{~mm}^{3}$ were printed on an $\mathrm{Al}$ alloy build plate under the protection of a high-purity argon gas atmosphere to lower the oxygen content below $0.1 \%$ to minimize oxidation. The second set of samples was the replicate of the first set in terms of process parameters. The build plate was preheated to $200{ }^{\circ} \mathrm{C}$ to decrease the temperature difference along the building direction and reduce the residual stresses. As summarized in Table 3, using a fixed platform downward displacement of $30 \mu \mathrm{m}$ (as recommended by the machine manufacturer for AlSi10Mg alloy), different laser powers, scanning speeds and hatch spacings were employed. As illustrated in Figure 4 , the scanning of layers was conducted using a stripe hatching pattern, alternating $90^{\circ}$ between subsequent layers. The stripe hatching pattern was employed to provide a more homogeneous distribution of residual stress compared to the meander hatching pattern and higher building rate than the chessboard hatching pattern [44]. The main reason behind applying $90^{\circ}$ rotation between subsequent layers was the ease of melt pool size and shape characterizations with higher accuracy. To reduce the chance of recoater jamming, the coupons were placed at a $20^{\circ}$ angle to the recoating direction.

Table 3. The process parameters employed to fabricate parts.

\begin{tabular}{cccc}
\hline Laser Power, $\boldsymbol{P}(\boldsymbol{W})$ & Scanning Speed, $\boldsymbol{v}(\mathbf{m m} / \mathbf{s})$ & Hatch Spacing, $\boldsymbol{h}(\mathbf{m m})$ & $\begin{array}{c}\text { Platform downward } \\
\text { displacement }(\mathbf{m m})\end{array}$ \\
\hline $300,335,370$ & $800,1050,1300$ & $0.15,0.19$ & 0.03 \\
\hline
\end{tabular}




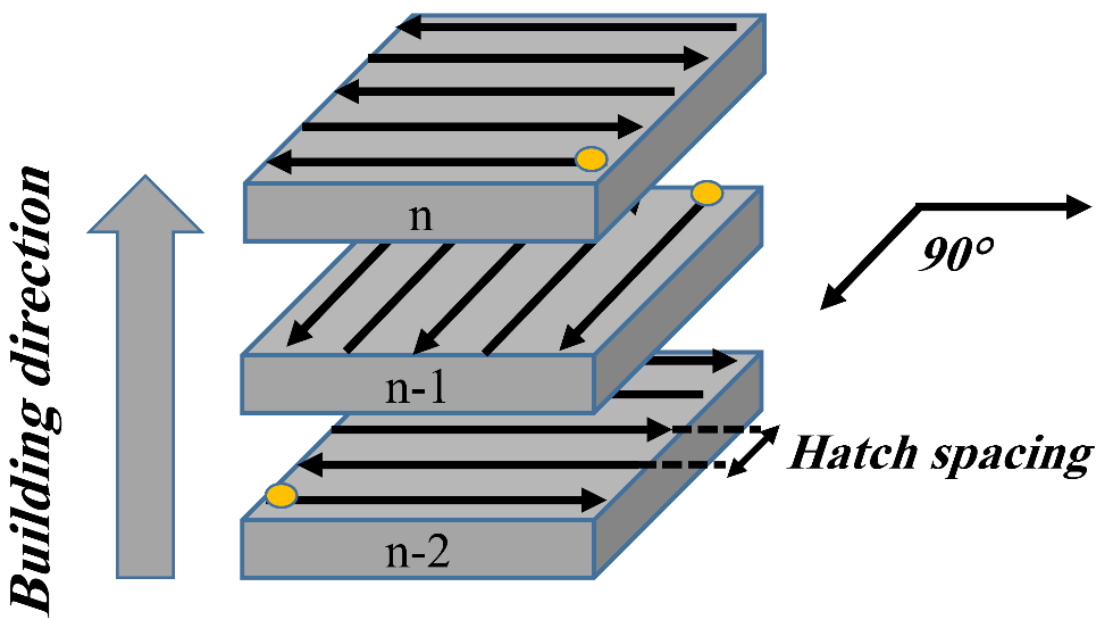

Figure 4. Schematic of the employed stripe hatching pattern scanning strategy, alternating $90^{\circ}$ between subsequent layers.

\subsection{Characterization of L-PBF-fabricated parts (densification level, dimensional accuracy, surface quality, microstructure and microhardness)}

The densification level of L-PBF fabricated parts was measured using the Archimedes method in accordance with the ASTM B296-17 standard [45]. The reported relative density is the average of at least five measurements from different parts manufactured with the same process parameters. The bulk density of AlSi10Mg parts was selected as $2.68 \mathrm{~g} / \mathrm{cm}^{3}[46,47]$.

Dimensional accuracy and flatness of as-built coupons were measured using a coordinate measuring machine $(\mathrm{CMM})$ having an accuracy of $0.1 \mu \mathrm{m}$. Measurements were done by recording 8 points on each surface of each coupon except the bottom surface to create planes. The distance between two parallel planes in $\mathrm{X}$ and $\mathrm{Y}$ directions is measured, respectively, along with the degree of flatness of each plane. The top surface of L-PBF fabricated parts was analyzed using SEM with an accelerating voltage of $20 \mathrm{kV}$ as well as Alicona Infinite Focus G5 microscope (Alicona Manufacturing Inc., Bartlett, IL, USA) which generates real 3D surface images by varying the focus. While providing valuable information about the surface integrity, the surface roughness of the additively manufactured parts was also evaluated by employing the Alicona microscope. The surface roughness reported in this study is the arithmetic mean surface roughness value $\left(S_{a}\right)$. The measurements were repeated five times for each part, and the mean value was reported as the surface roughness.

The defects were characterized by observing the front section of parts using a Nikon optical microscopy $(\mathrm{OM})$. For this purpose, the front sections were ground and polished according to the standard metallography procedure. To observe the microstructural evolution in the L-PBF fabricated parts, the 
polished samples were etched chemically using Keller's Reagent and were characterized by OM as well as SEM operating at an accelerated voltage of $10 \mathrm{kV}$.

Microhardness measurements were performed by employing a Matsuzawa microhardness testing machine with a load of $200 \mathrm{~g}$ being applied for $10 \mathrm{~s}$. The reported microhardness represents the average of at least 9 measurements for each specimen.

\section{Results and Discussion}

\subsection{Flowability and packing density}

The results of powder flowability measurements obtained by Hall flowmeters and FT4 powder rheometer are provided in Table 4. The fine AlSi10Mg powder flowed through the funnel neither in Hall nor in Carney flowmeter. However, the coarse AlSi10Mg powder experienced free flow even in the Hall flowmeter with a time of $\sim 76 \mathrm{~s}$ for $50 \mathrm{~g}$ of powder. Based on the Hall and Carney flowmeter measurements, the coarse powder was found to be more flowable compared to the fine one. However, a quantitative comparison between the flowability of fine and coarse powder systems is only available by the FT4 powder rheometer method in which both powders can flow. The higher the BFE or SE in the FT4 test, the lower the powder flowability. The BFE and SE results derived from the FT4 test measurements were not in agreement in terms of introducing the powder with higher flowability. From the BFE index perspective, the fine powder showed a higher flowability. However, from the SE viewpoint, the coarse powder was found to be more flowable. Since the powder/blade interaction during the upward motion of the blade is closer to the powder/recoater interactions during the powder spreading stage in the L-PBF process, SE is a better representative of the powder flowability [29]. Based on the SE results provided in Table 4, the flowability of fine powder is $75 \%$ lower than that of the coarse one. This is attributed to the intensive cohesive forces existing among the fine powder particles with significantly large specific surface area relative to volume, which results in noticeably high inter-particle friction and low powder flowability [48-50].

Table 4. The results of Hall flowmeter and FT4 Freeman powder rheometer techniques presenting the flowability and density of powders.

\begin{tabular}{|c|c|c|c|c|}
\hline \multirow{3}{*}{$\begin{array}{l}\text { AlSi10Mg } \\
\text { Powder }\end{array}$} & \multicolumn{3}{|c|}{ Powder Flowability } & \multirow{3}{*}{$\begin{array}{c}\text { Powder Density } \\
\text { Conditioned Bulk Density-CBD } \\
(\mathrm{g} / \mathrm{mL})\end{array}$} \\
\hline & \multirow{2}{*}{$\begin{array}{c}\text { Hall Flowmeter } \\
\text { Flow Time } \\
(\mathrm{sec})\end{array}$} & \multicolumn{2}{|c|}{ FT4 Powder Rheometer } & \\
\hline & & $\begin{array}{c}\text { Basic Flow Energy, } \\
\text { BFE }(\mathrm{mJ})\end{array}$ & Specific Energy, SE (mJ/g) & \\
\hline Coarse & $76.54 \pm 0.6$ & $234.2 \pm 10.08$ & $2.606 \pm 0.068$ & $1.424 \pm 0.003$ \\
\hline Fine & No flow & $99.85 \pm 3.27$ & $4.568 \pm 0.193$ & $1.019 \pm 0.027$ \\
\hline
\end{tabular}


The CBDs of the fine and coarse AlSi10Mg powders are also summarized in Table 4. The measurements revealed a major difference between the densities of fine and coarse powder systems. The coarse powder showed $\sim 43 \%$ higher density compared to the fine powder due to the higher population of interstices, more inter-particle frictions, and the higher chance of agglomeration in the fine powder feedstock. The relative densities with respect to the bulk density of AlSi10Mg alloy (i.e., $2.68 \mathrm{~g} / \mathrm{mL}$ ) would be $53 \%$ and $38 \%$ for coarse and fine powders, respectively. Since the powder/blade interactions through the density measurement by the FT4 method resembles that of PBF-AM processes, the relative powder bed packing density is estimated to be around the same values as well [29].

\subsection{Laser absorptivity}

The reflectance results obtained by the DRS test were converted to the Kubelka-Munk (K-M) absorption factor to quantitatively compare the absorption behavior of powders using the K-M equation as [51]:

$f(R)=K / S=(1-R)^{2} / 2 R$

Eq. 4

where $R$ is the reflectance of the powder, $K$ is the absorption coefficient, and $S$ represents the scattering coefficient. Figure 5 shows the variation in the $R$ and K-M absorption factor for both powders as a function of the wavelength. At the wavelength of $1070 \mathrm{~nm}$, which is the wavelength for most of the commercially available L-PBF machines, including the EOS M290 employed in the present research, the $R$ of the fine powder was $\sim 2 \%$ lower than that of the coarse powder. Since the transmittance of the metallic powder as an opaque object is negligible, the absorption can be estimated as (1- $R$ ). Accordingly, the absorptance of the fine powder is $\sim 2 \%$ higher than the coarse one $58 \%$ and $60 \%$ for coarse and fine powder systems, respectively). From the K-M absorption factor perspective, the fine powder was found to be $\sim 13 \%$ more absorptive to the laser compared to the coarse powder. The higher absorption of the fine powder is due to the: (i) higher specific surface area relative to volume of powder particles and (ii) the entrance of more light and consequently more internal interaction caused by the lower packing density of the fine powder. However, based on the microstructural observations of powders provided in Figure 2(c) and (d), the agglomerates formed in the fine powder feedstock act to decrease the specific surface area relative to volume and consequently decline the absorption. In addition, the slightly higher (not significant) absorption of the fine powder can also be ascribed to the major dependence of the absorptivity on the material. The research studies have shown that the absorption of metallic materials with a relatively high laser absorptivity (e.g., AlSi10Mg alloy used in this study) is not highly dependent on the particle size distribution [52, 53]. 


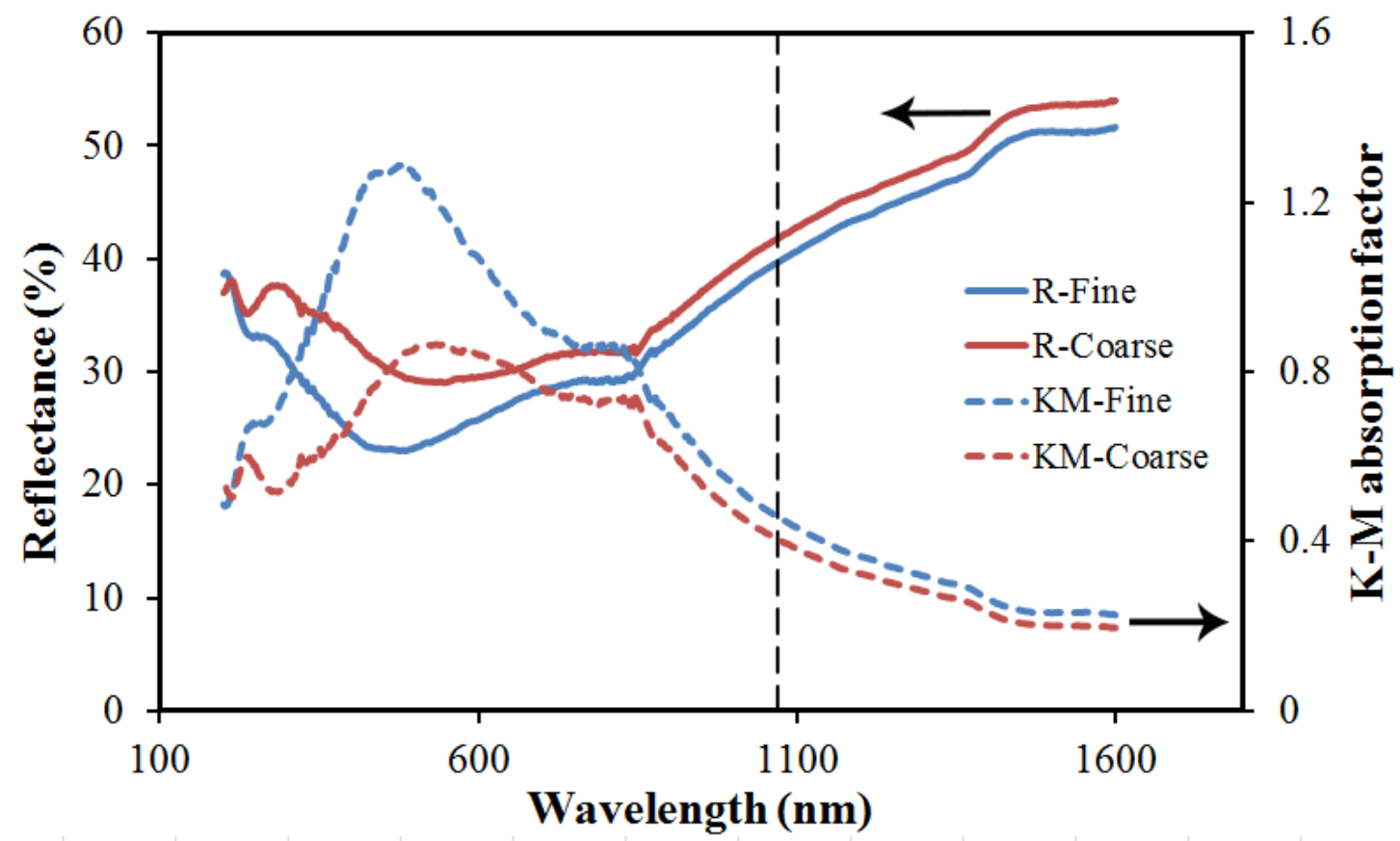

Figure 5. The variation in the reflectivity and the K-M absorption factor of fine and coarse AlSilOMg powders as a function of the wavelength. The dashed vertical line (wavelength of $1070 \mathrm{~nm}$ ) represents the laser wavelength of the L-PBF machine used in this study.

\subsection{Density-laser energy input relationship}

Energy density is usually used as a metric to compare the parts fabricated by the L-PBF process under different sets of process parameters. The volumetric energy density $\left(e_{V}\right)$ is the most widely used energy density in the literature, which is defined as $[10,54]$ :

$e_{V}=\frac{P}{v h t}$

Eq. 5

where $P, v, h$, and $t$ denote the laser power, scanning speed, hatch spacing and powder layer thickness, respectively. The powder layer thickness is often mistaken for the platform downward displacement [55]. After the laser processing of the first deposited powder layer with the thickness of $t$, the consolidated layer is believed to have a lower thickness due to the presence of inter-particle pores within the powder bed. In other words, the molten material formed due to the powder/laser interaction fills the interstices and leads to a dense solidifies layer with a thickness lower than $t$. Therefore, a gap is created between the top surface of the consolidated layer and the tip of the recoater. Afterward, the platform moves downward for another $t$, and the recoater deposits the second powder layer. However, due to the presence of the free height formed as a result of the first layer consolidation, the thickness of the deposited powder in the second layer will be larger than $t$. It means that the thickness of the powder bed in the second layer is higher than the nominal value/platform displacement $(t)$ considered as the powder layer thickness in Eq. 5. Further deviation from $t$ occurs as the next powder layers are deposited and consolidated until the powder layer thickness approaches a constant value governed by the $t$ and the powder bed packing density. The powder layer 
thickness in the steady-state condition is known as the "effective powder layer thickness $\left(t_{e f f}\right)$ " which is larger than $t$ [31]. To compensate the error associated with ignoring the actual powder layer thickness, $t_{\text {eff }}$ should be substituted in Eq. 5. In addition, this equation assumes the laser absorptivity of the powder as $100 \%$. However, since the laser absorptivity is dependent on the material and particle size, the laser absorptivity coefficient $(K)$ needs to be involved in the volumetric energy density equation as well. By taking the $t_{e f f}$ and $K$ into account, the energy input can be defined with a new perspective as:

$E_{V}=\frac{K P}{v h t_{\text {eff }}}$

This equation takes the effect of both the process parameters and the powder properties into account. In most of the research studies which have investigated the effect of process parameters on the densification of a single material with a fixed powder system, the application of this equation would only shift the energy input results to lower values. However, when it comes to the comparison between different materials or different powders of the same material, calculation of the energy density based on Eq. 5 would be misleading. Therefore, to establish a correlation between the densification level of the L-PBF processed parts and the energy input, $E_{V}$ (Eq. 6) was used in this study. By considering the platform displacement of $30 \mu \mathrm{m}$ and relative powder bed packing densities of $53 \%$ and $38 \%$ (section 3.1 ), $t_{\text {eff }}$ was calculated to be 56.3 and $78.8 \mu \mathrm{m}$ for coarse and fine powder systems, respectively. By substituting the calculated $t_{e f f}$ and the measured $K$ value (section 3.2) in Eq. $6, E_{V}$ would be $12.5-28.8 \mathrm{~J} / \mathrm{mm}^{3}$ and $9.3-21.3 \mathrm{~J} / \mathrm{mm}^{3}$ for the coarse and fine powder systems within the applied range of process parameters, respectively.

The results of relative density as a function of the $E_{V}$ for parts fabricated by both fine and coarse powder systems are shown in Figure 6(a). The density measurement results are quite reliable, with a maximum coefficient of variation less than $1.3 \%$ for both powder systems. With one exception, the relative density is lower than $95 \%$ in the case of fine powder. However, highly dense samples with relative densities up to 99\% are achieved in the case of coarse powder feedstock. In general, the relative density of the parts fabricated by the coarse powder was up to $4.6 \%$ higher than that of the fine powder case. Since the calculated standard deviations of the measured relative densities vary between $0.1-1.1 \%$ for both cases, the differences between relative densities of the fine and coarse powder cases are statistically significant. The optimum samples in terms of density for both coarse and fine powders are shown in Figure 6(b) and (c). Although their $E_{V}$ are different, the laser power, scanning speed and hatch spacing of optimum samples are the same for both cases $(P=335 \mathrm{~W}, v=1050 \mathrm{~mm} / \mathrm{s}$ and $h=0.15 \mathrm{~mm})$. In the following section, the reasons behind the inferior densification levels in the case of the fine powder system are explored. 

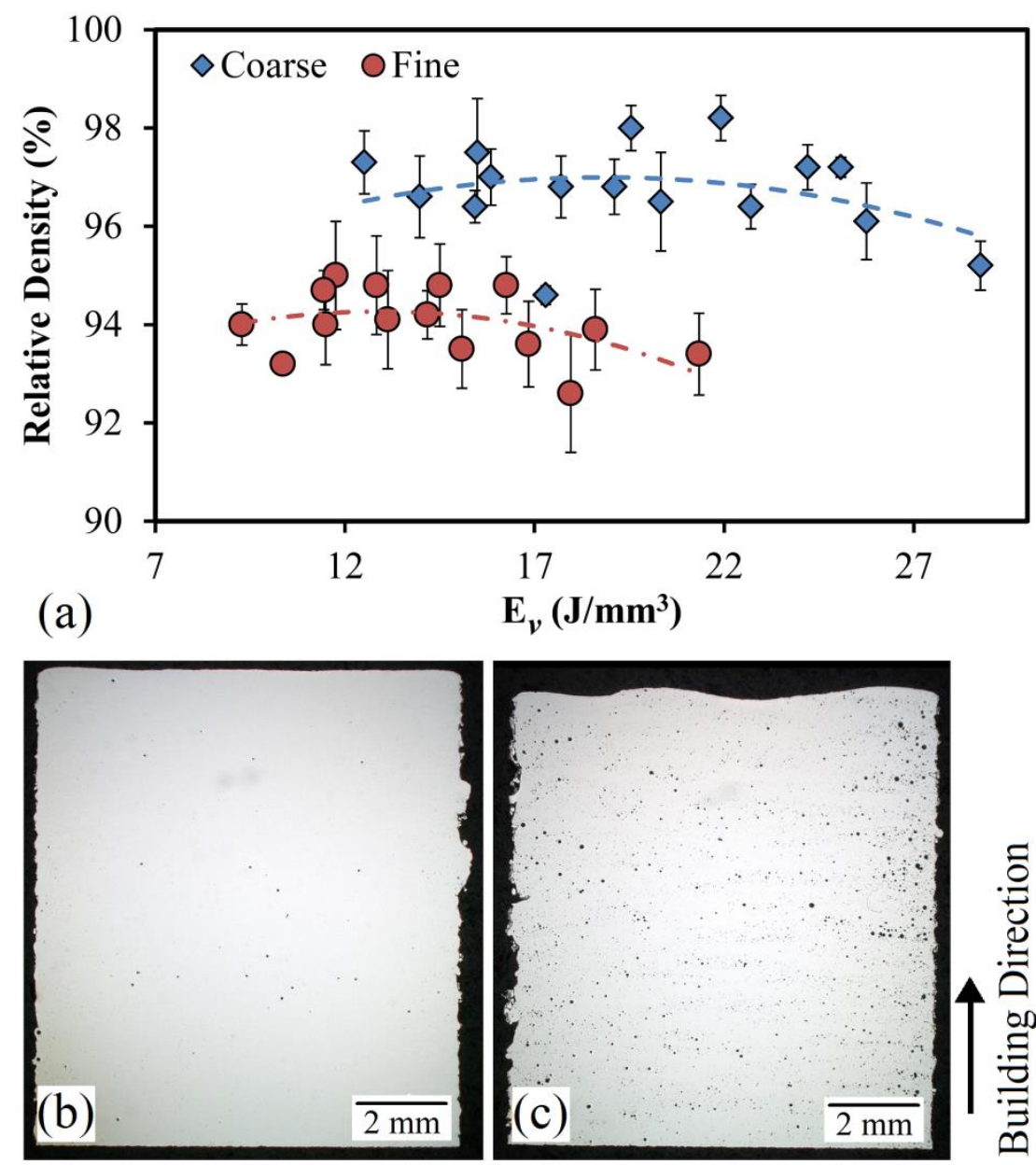

Figure 6. (a) The variation in the density of L-PBF fabricated AlSilOMg parts as a function of the volumetric energy density $\left(\boldsymbol{E}_{\boldsymbol{V}}\right) .(b)$ and (c) Cross-sectional optical micrographs of parts with the optimum density obtained by L-PBF processing of coarse $\left(\boldsymbol{P}=335 \mathrm{~W}, \boldsymbol{v}=1050 \mathrm{~mm} / \mathrm{s}, \boldsymbol{h}=0.15 \mathrm{~mm}\right.$ and $\left.\boldsymbol{E}_{V}=21.9 \mathrm{~J} / \mathrm{mm} 3\right)$ and fine $(\boldsymbol{P}=335 \mathrm{~W}, \boldsymbol{v}=1050$ $\mathrm{mm} / \mathrm{s}, \boldsymbol{h}=0.15 \mathrm{~mm}$ and $\boldsymbol{E}_{\boldsymbol{V}}=16.3 \mathrm{~J} / \mathrm{mm} 3$ ) AlSilOMg powders, respectively.

\subsection{Densification level}

Referring to Figure 6, the fabrication of almost fully dense AlSi10Mg parts with fine powder feedstock seems to be impossible. Although the fine powder was expected to show higher kinetics of densification due to the smaller size and higher absorptivity, the results are suggesting otherwise. To understand the fundamental reasons behind the inferior densification level of parts obtained by the fine powder, the factors dictating the density of L-PBF processed parts need to be investigated.

Powder bed packing density: One of the most important factors affecting the part density in PBF-AM processes is the powder bed packing density [27]. Lower relative powder bed densities are accompanied by a higher volume fraction of pores within the powder bed. This consequently makes it rather challenging for the molten material to fill all of the interstices due to the rapid solidification nature of the L-PBF process [56]. Not only can the volume fraction of pores within the powder bed, but also their size can play a 
significant role in the densification level of the final printed part. While tiny inter-particle porosities can be easily filled by the molten material, the large pores have a lower chance of being filled, especially at high laser scanning speeds. Presence of large particle agglomerates which are not able to settle on the substrate (larger than $t_{e f f}$ in size) is believed to be one of the main sources for the formation of large voids within the powder bed. These agglomerates can also sweep the powder particles ahead of them and further influence the powder bed packing density [57]. Since the powder particles in the fine powder system tend to create agglomerates to alleviate their considerably high surface energy (Figure 2(c) and (d)), the existence of large voids within the powder bed of fine powder feedstock is highly probable [16]. Moreover, the significantly lower flowability of the fine powder feedstock compared to the coarse one (Table 4) can also generate large vacancies within the powder bed. According to the CBD measurement results, the relative powder bed density is $53 \%$ and $38 \%$ for coarse and fine powder systems, respectively. Accordingly, the volume fraction of pores in the bed of fine powder is $32 \%$ higher than that of the coarse one. This reveals that the filling of pores requires a significantly longer period during the processing of the fine powder, which is not available in the L-PBF process due to its rapid melting/solidification nature. Figure 7 shows optical micrographs of parts manufactured at a high scanning speed of $1300 \mathrm{~mm} / \mathrm{s}$ and various laser powers. As it is evident, there is almost no defect in the case of the coarse powder system (Figure 7(a)-(c)). However, large pores which are free from un-melted/partially melted powder particles are visible in samples fabricated by the fine powder feedstock. The absence of un-melted/partially melted powder particles in most of these pores proves that they are formed due to the limited flow of the molten material to fill the large voids within the powder bed [58]. The fraction of these large pores shows a descending trend by increasing the laser power, which can be attributed to the larger melt pool, lower melt viscosity, lower cooling rate and higher chance of the molten material to fill the pores (Figure 7(d)-(f)) [59-61]. That is why the large pores are almost eliminated at the laser power of $370 \mathrm{~W}$ in the fine powder system (Figure 7(f)). 

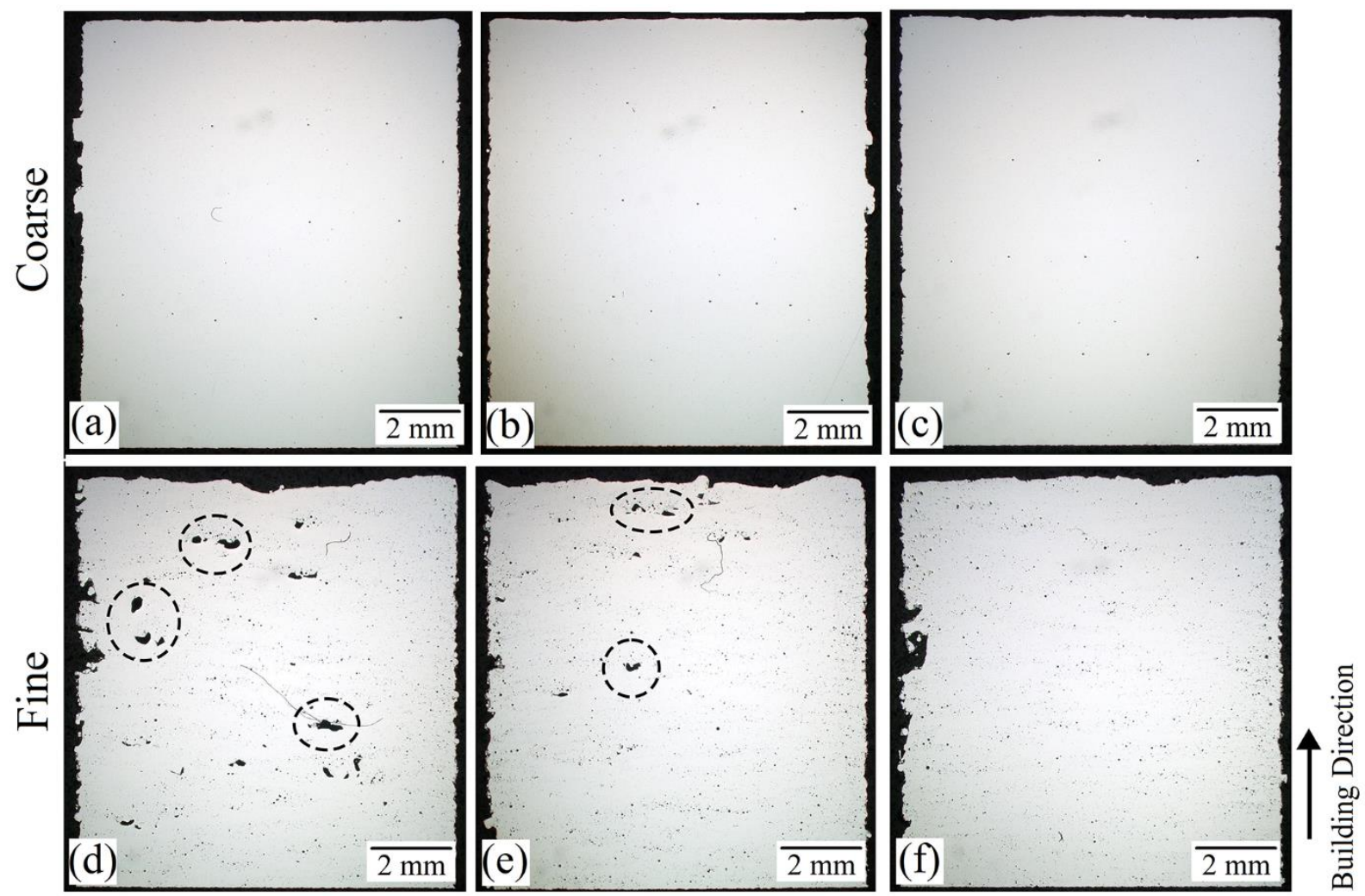

Figure 7. Cross-sectional non-etched optical micrographs of parts obtained by L-PBF processing of: (a)-(c) coarse and (d)-(f) fine AlSilOMg powders. The employed hatch spacing and scanning speed are $0.15 \mathrm{~mm}$ and $1300 \mathrm{~mm} / \mathrm{s}$ for all samples while the laser powder is: (a), (d) $300 \mathrm{~W} ;(b),(e) 335 \mathrm{~W}$ and (c), (f) $370 \mathrm{~W}$.

Evaporation and oxygen content: Another factor which is mainly dominant at low scanning speeds is the material evaporation caused by the high $E_{V}$ [59]. The evaporated AlSi10Mg and the entrapped oxygen gas would lead to the formation of spherical porosities in the final parts. Although the significantly higher $t_{e f f}$ of the fine powder favors lower $E_{V}$ at the same process parameters, more evaporation is expected to take place when the fine powder is employed. This is due to the fact that the melting of individual powder particles and their evaporation is way easier in the fine powder system. The energy required to melt a single powder particle over the average energy of the laser beam can be calculated as [32]:

$\frac{E_{\text {need }}}{E_{\text {av }}}=\frac{\left(4 /{ }_{3} \pi r^{3}\right) \cdot \rho \cdot\left(c \Delta T_{m}+L_{m}\right)}{K \cdot I_{0} \cdot \pi \cdot r^{2}}=r \cdot \frac{4 \rho\left(c \Delta T_{m}+L_{m}\right)}{3 K I_{0}}$

in which $r, \rho, c, \Delta T_{m}, L_{m}, K$ and $I_{0}$ denote the particle radius, density, specific heat capacity, temperature rise up to the melting point, latent heat of fusion, the absorption coefficient of the powder and the intensity of the laser beam, respectively. As it is evident, the finer the powder particle (smaller $r$ ) and the higher the absorption coefficient $(K)$, the lower the energy required for melting and, therefore, evaporation. On the other hand, due to their higher specific surface area relative to volume, fine powders show a higher degree of contamination and are more prone to oxidation [62]. For instance, calculations for a portion of the powder bed with a volume of $10 \times 10 \times t_{\text {eff }}$ revealed that the number of particles and their surface area in the fine 
powder system are 88 and 4.5 times greater than those of the coarse powder feedstock, respectively. In this calculation, all of the powder particles in each system are assumed to have a diameter equal to their average powder particle size ( 9 and $40 \mu \mathrm{m}$ for fine and coarse powders, respectively). It can be inferred from these calculations that the volume and, therefore, the mass fraction of the oxide layers existing on the surface of particles (e.g., $\mathrm{MgAl}_{2} \mathrm{O}_{5}$ detected on the surface of $\mathrm{AlSi10Mg}$ powder particles [63]) in the fine powder feedstock are 4.5 times greater than that of the coarse powder. These oxide films usually have a melting point noticeably higher than that of metallic powders. However, they can be decomposed during the L-PBF process. Since the rapid solidification of the melt pool can hinder the generated oxygen/evaporated material to escape from the melt pool, the entrapped gas bubbles can lead to spherical porosities in the final part, which is more severe in the fine powder system due to its higher mass fraction of oxide layers. Figure 8 shows optical micrographs of parts manufactured at a low scanning speed of $800 \mathrm{~mm} / \mathrm{s}$ and various laser powers. It can be seen that the dominant defects in these samples are spherical pores which are present in both samples fabricated by coarse and fine powder feedstocks. However, their volume fraction is higher in the case of the fine powder system (Figure 8(d)-(f)). The volume fraction of pores follows an ascending trend by increasing the laser power in both cases. This is attributed to the increased evaporation of the molten material and the intensified oxide decomposition caused by the increase in the $E_{V}$. 

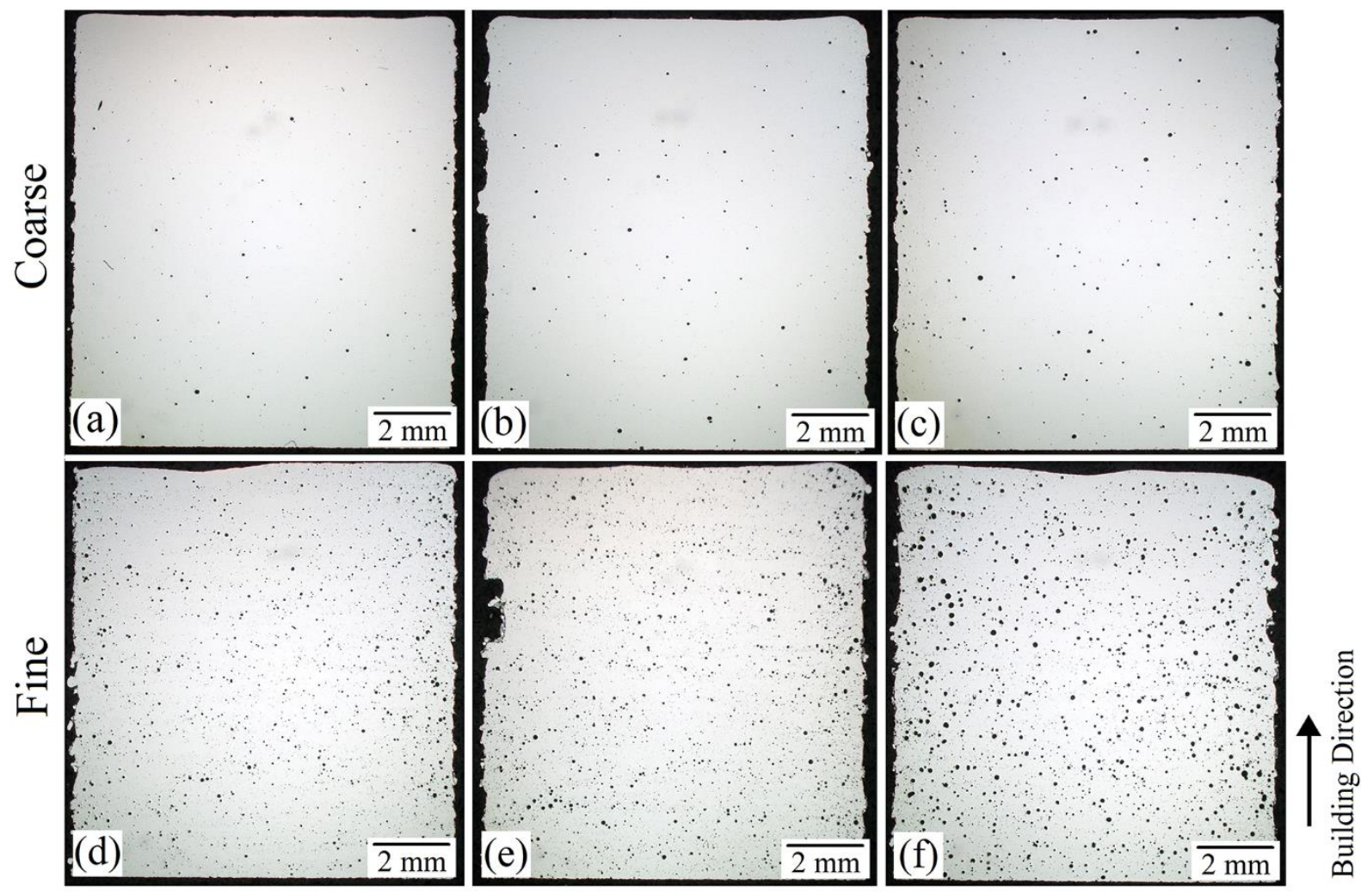

Figure 8. Cross-sectional non-etched optical micrographs of parts obtained by L-PBF processing of: (a)-(c) coarse and $(d)-(f)$ fine AlSilOMg powders. The employed hatch spacing and scanning speed are $0.19 \mathrm{~mm}$ and $800 \mathrm{~mm} / \mathrm{s}$ for all samples while the laser powder is: $(a),(d) 300 \mathrm{~W},(b),(e) 335 \mathrm{~W}$, and $(c),(f) 370 \mathrm{~W}$.

Effective powder layer thickness $\left(t_{\text {eff }}\right)$ : Although rarely observed, un-melted or partially melted powder particles were also present in some of the parts fabricated by L-PBF processing of fine powder feedstock at low $E_{V}$. None of the parts had un-melted/partially melted powder particles within the applied range of process parameters when the coarse powder was used. This can be ascribed to the lower $t_{\text {eff }}(56.3 \mu \mathrm{m})$ and the negligible tendency of coarse powder particles to form agglomerates. Figure 9 shows an irregular-shape defect which was formed due to the incomplete fusion of fine powder particles at $E_{V}=9.3 \mathrm{~J} / \mathrm{mm}^{3}$ (the minimum $E_{V}$ in this study). Although the extremely large agglomerates cannot settle on the substrate during the spreading stage, clusters less than $t_{e f f}(78.5 \mu \mathrm{m})$ in size can be deposited. At low $E_{V}$, the laser cannot completely melt the deposited agglomerates, leading to the formation of defects which contain unmelted/partially melted powder particles (Figure 9(b)). These particles seem to be sintered and fused together due to the thermal cycles induced during the processing of the adjacent tracks/next layers (Figure $9(\mathrm{~b}))$. 

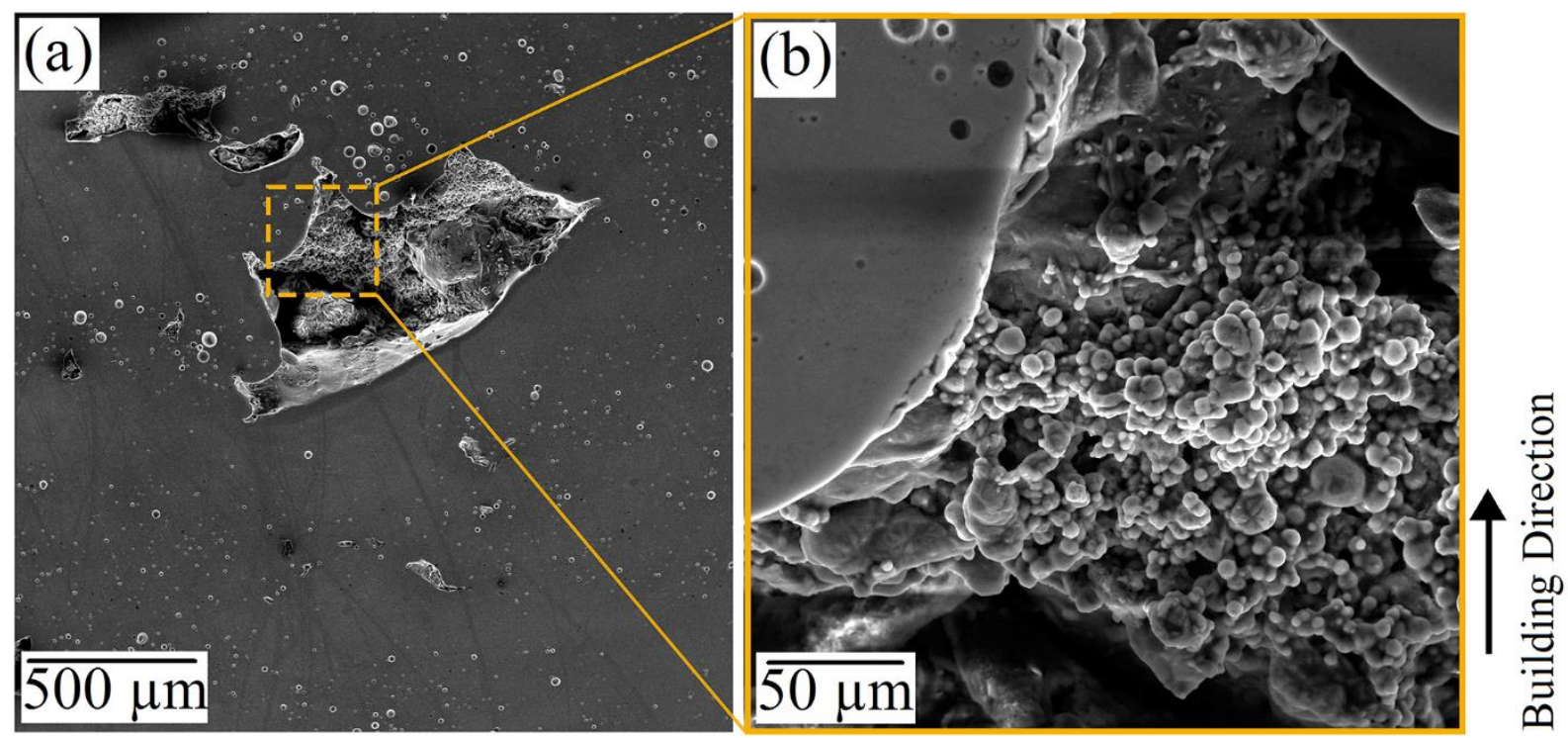

Figure 9. SEM micrographs from the cross-section of part obtained by L-PBF processing of the fine AlSilOMg powder employing laser power of $300 \mathrm{~W}$, scanning speed of $1300 \mathrm{~mm} / \mathrm{s}$ and hatch spacing of $0.19 \mathrm{~mm}\left(\boldsymbol{E}_{\boldsymbol{V}}=9.3\right.$ $\mathrm{J} / \mathrm{mm}^{3}$ ). (b) Shows the higher magnification micrograph of the selected region in (a).

\subsection{Top surface quality}

Since in the L-PBF process, the components are fabricated through a layer-by-layer manner, the top surface of each consolidated layer acts as the substrate for the deposition of the next powder layer. Therefore, the top surface (not the side surface) quality of the consolidated layer plays a major role in the powder spreading process, powder bed packing density, and, consequently, the densification level of the next powder layer. Given the fact that the top surface of the last layer in the printed part resembles the top surface of every single consolidated layer during the process, its characterization provides valuable information about the quality of the final part. Figure 10 presents SEM micrographs of the top surface for parts manufactured by fine and coarse powders using various scanning speeds. A qualitative comparison of the surfaces reveals the worsening of the surface quality by increasing the scanning speed. For the sake of quantitative analysis, top surfaces were also analyzed using 3D surface topography measurements. Figure 11 shows the effect of scanning speed on the surface topography of samples obtained by both fine and coarse powders as well as the $S_{a}$ values corresponding to these surfaces. Within the applied range of process parameters, fine powder resulted in higher surface roughness compared to the coarse powder. Depending on the employed scanning speed, the difference between the $S_{a}$ of fine and coarse powder cases was found to be 5-73\%, with higher scanning speeds resulting in a larger difference in the $S_{\mathrm{a}}$. 

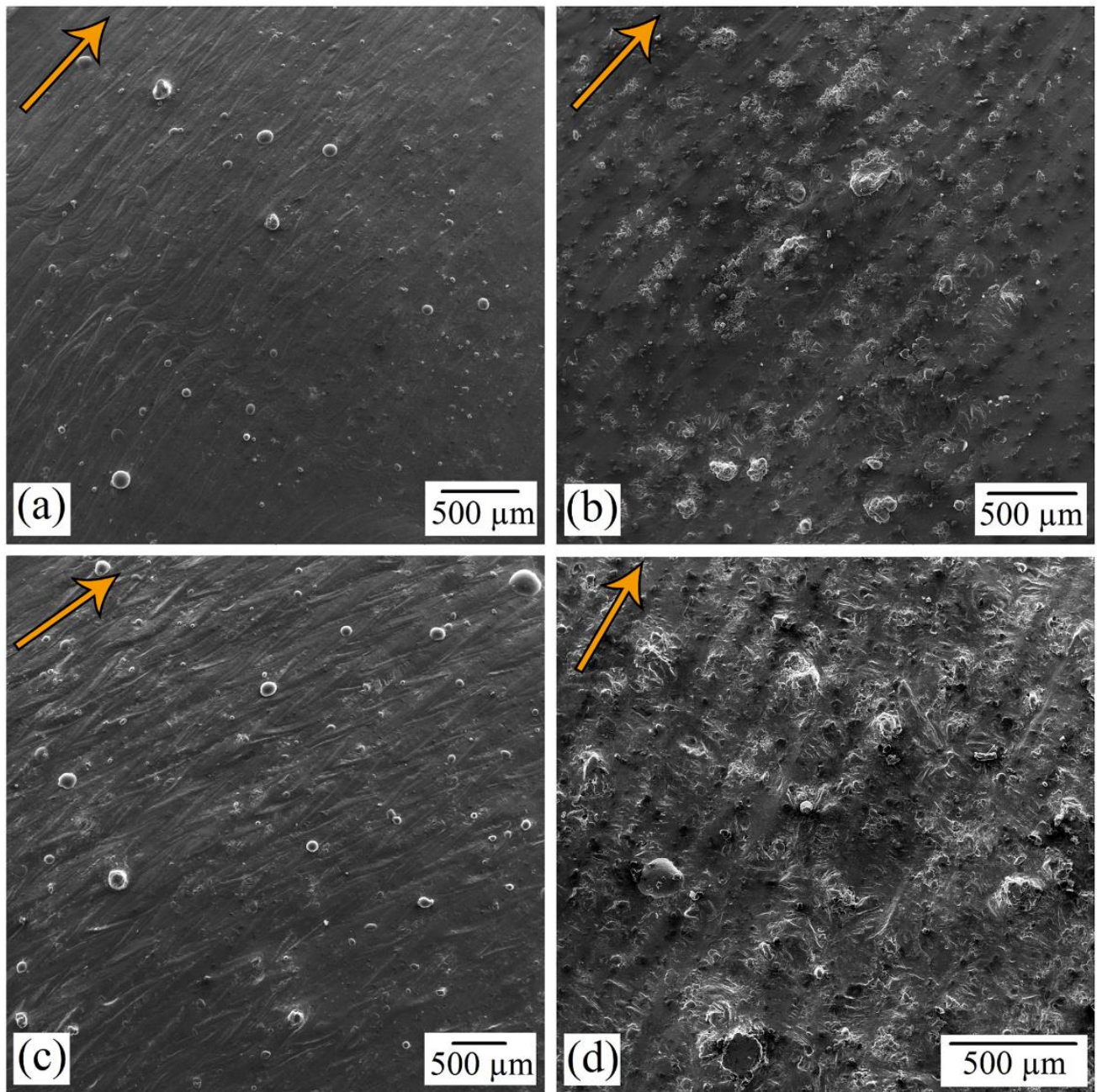

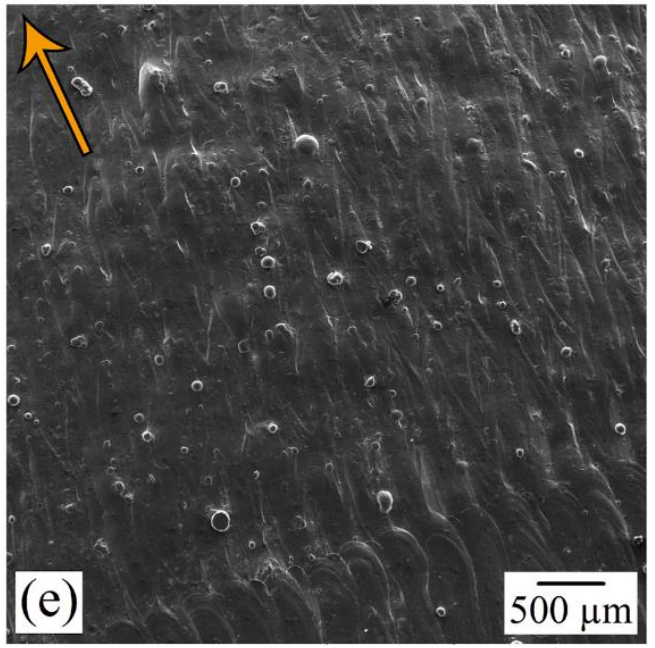

Coarse

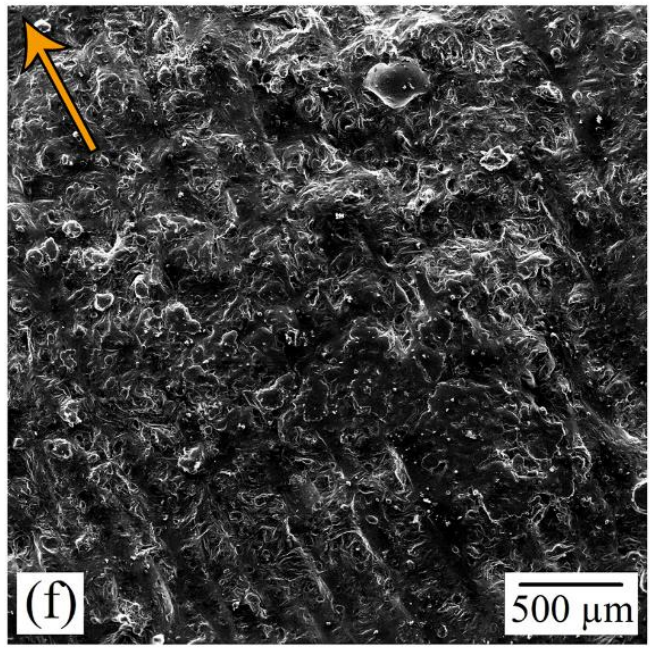

Fine

Figure 10. SEM micrographs of the top surface for parts manufactured by L-PBF processing of: (a), (c), (e) coarse and $(b),(d),(f)$ fine AlSilOMg powders. The parts have been processed by a fixed laser power of $335 \mathrm{~W}$ and $a$ constant hatch spacing of $0.15 \mathrm{~mm}$ but varying scanning speeds of: $(a)$ and $(b)$ 800; $(c)$ and $(d)$ 1050; (e) and (f) $1300 \mathrm{~mm} / \mathrm{s}$. The arrows show the scanning direction. 

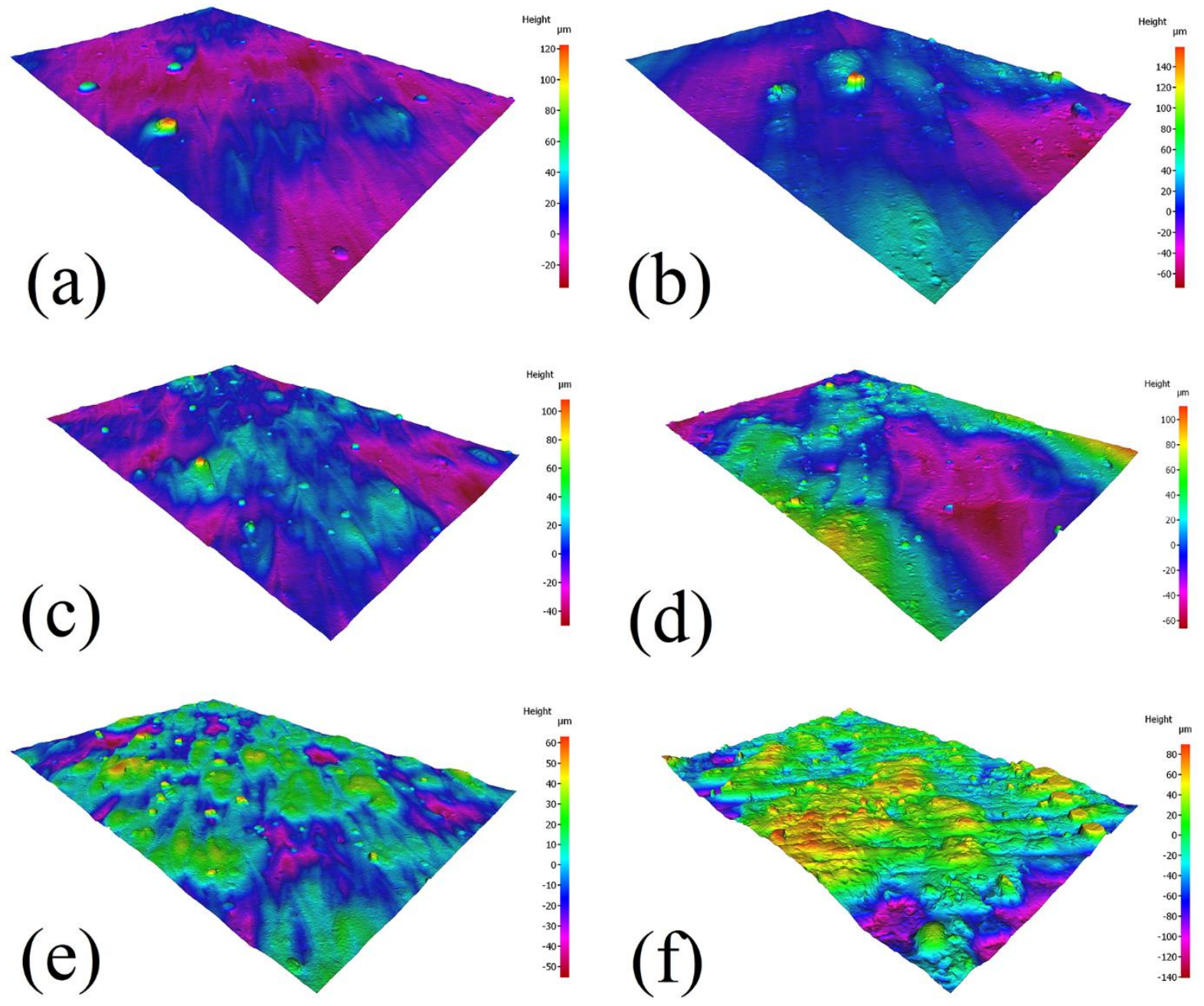

\begin{tabular}{|c|c|c|c|c|c|c|}
\hline \multirow{2}{*}{ Sample } & \multicolumn{3}{|c|}{ Coarse powder } & \multicolumn{3}{c|}{ Fine powder } \\
\cline { 2 - 7 } & (a) & (c) & (e) & (b) & (d) & (f) \\
\hline Sa $(\boldsymbol{\mu m})$ & 3.75 & 4.59 & 7.25 & 3.93 & 5.17 & 12.52 \\
\hline
\end{tabular}

Figure 11. Color-3D images showing the top surface topography of parts produced by L-PBF processing of: (a), $(c),(e)$ coarse and (b), (d), (f) fine AlSilOMg powders. The roughness of the provided surfaces is also listed in the table. The parts have been processed by a laser power of $335 \mathrm{~W}$ and a hatch spacing of $0.15 \mathrm{~mm}$ but varying scanning speeds of: (a) and (b) 800; (c) and (d) 1050; (e) and (f) $1300 \mathrm{~mm} / \mathrm{s}$.

Although it has been reported in the literature that application of fine powders can lead to the fabrication of parts with the improved surface quality due to the decrease in the size of un-melted/partially melted particles on the surface $[64,65]$, the surface roughness obtained by the fine powder feedstock is lower than the coarse one regardless of the applied scanning speed. Referring to Figure 10, the surface in both cases is almost free from un-melted/partially melted powder particles, suggesting that the variation in the surface roughness cannot be attributed to these particles. The reason behind the higher top surface roughness of samples fabricated by the fine powder can be unveiled through the analysis of the oxygen content. Figure 
12 shows the oxygen concentration for the top surface of parts fabricated by fine and coarse powders with the same process parameters. As it is evident, the oxygen content in the case of fine powder is 2-7 times higher than that of the coarse powder system. The significantly higher specific surface area relative to volume of fine powder feedstock is the main reason behind its higher oxidation tendency, leading to the elevated oxygen content in the final part [62]. The presence of higher oxygen content in the melt pool results in the inward flow of the molten material due to the larger positive value of the surface tension gradient, encouraging the instability and discontinuity of the melt pool [66]. The locally disrupted tracks with the perturbed surface formed under such conditions lead to the higher top surface roughness. Moreover, higher content of oxygen is accompanied by the in-situ formation of oxides during the L-PBF process, which amplifies the surface roughness. It is also worth noting that some oxides existing in the fabricated parts may originate from the oxidation activated during the melting process [25]. On the other hand, the spattering phenomenon induced during the L-PBF process may vary by changing the particle size and size distribution which in turn affects the surface quality of the final parts [67, 68].

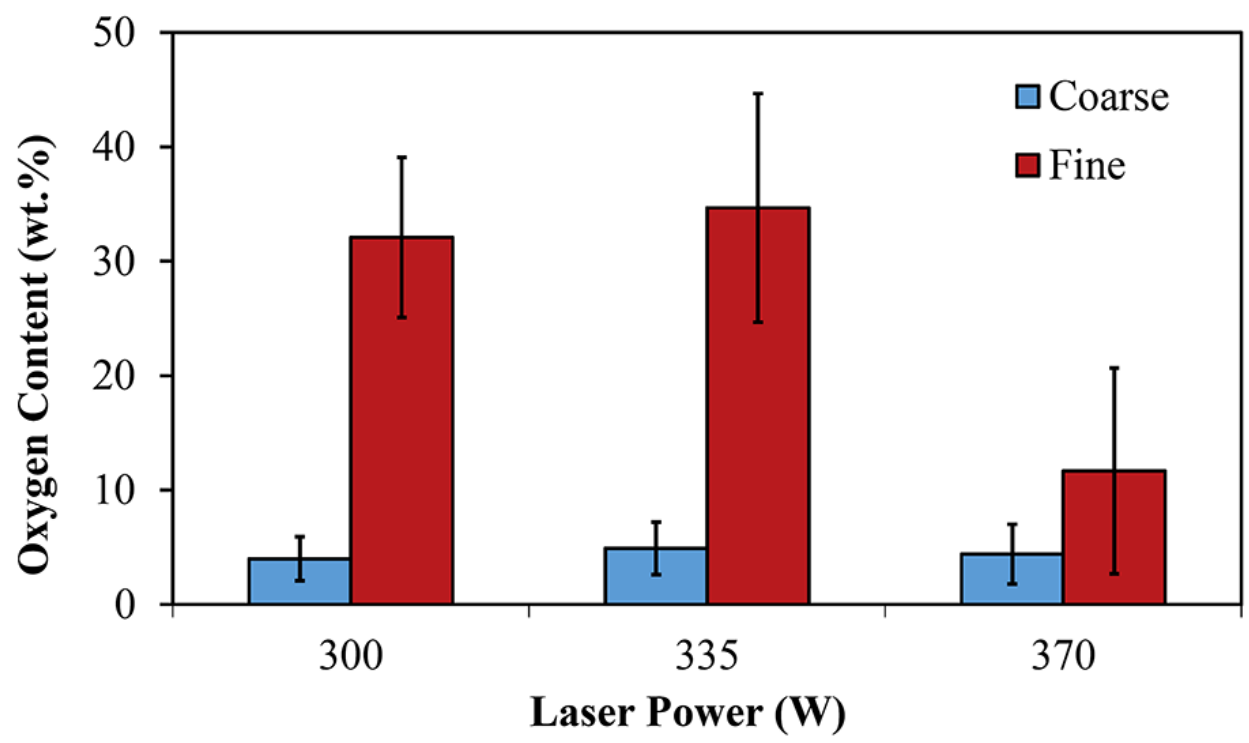

Figure 12. The oxygen concentration of parts obtained by L-PBF processing of coarse and fine AlSilOMg powders using various laser powders. The measurement has been performed by EDS analysis. The employed scanning speed and hatch spacing were $800 \mathrm{~mm} / \mathrm{s}$ and $0.15 \mathrm{~mm}$, respectively.

It should be borne in mind that the surface quality is affected by not only the surface roughness but also the surface waviness of the fabricated parts. Based on the powder flowability results provided in Table 4, the fine powder system suffers from a poor flowability, originating from the enhanced inter-particle friction and cohesiveness. The deteriorated spreadability caused by inter-particle friction, as well as the higher tendency of agglomeration due to the high cohesiveness, leads to the deposition of non-uniform powder layers during the recoating process [69]. Consequently, the layer consolidated from the fine powder shows a surface texture that is wavier (Figure 11). 


\subsection{Dimensional accuracy}

\subsubsection{X-Y plane}

Figure 13(a) illustrates the deviation in the area of X-Y plane (compared to the design dimensions of 10 $\mathrm{mm} \times 10 \mathrm{~mm}$ ) for parts printed from the coarse and fine powders using various linear laser energy densities $(P / v)$ and two different hatch spacings of 0.15 and $0.19 \mathrm{~mm}$. Compared to the case of coarse powder, the fine powder led to parts with higher deviations in the area within the employed range of $P / v$ ratio and hatch spacing.

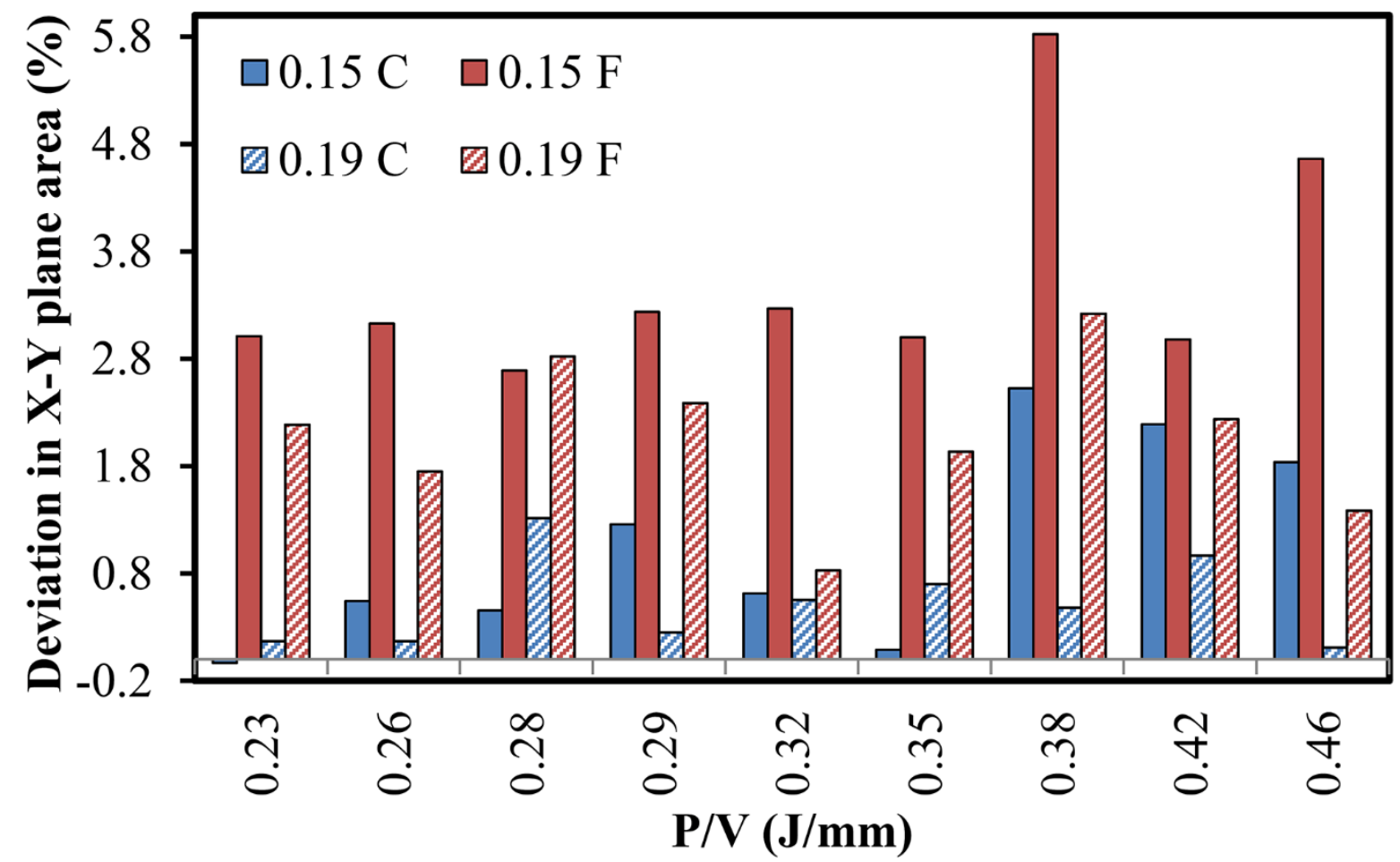

Figure 13. The deviation in the area of the X-Y plane in the cubic samples fabricated by L-PBF processing of fine $(F)$ and coarse $(C)$ AlSilOMg powders using various $\boldsymbol{P} / \boldsymbol{v}$ ratios and two different hatch spacings of 0.16 and 0.19 mm.

Microstructural observation of the side surface can provide valuable information regarding the in-plane dimensional accuracy. Figure 14 shows SEM micrographs of the side surface for parts obtained by L-PBF processing of coarse and fine powder feedstocks. The surface of the part processed from the coarse powder shows un-melted/partially melted powder particles and molten droplets attached to the surface (Figure 14(a) and (b)). Compared to the top surface of the same part provided in Figure 10(e), the side surface shows an inferior surface quality. The presence of un-melted/partially melted powder particles on the side surface is more significant in part produced by the fine powder (Figure 14). As shown in Figure 14(c) and (d), the side surface under this condition is noticeably rough and contains a large number of powder particles that 
seem to be attached to the molten tracks during the L-PBF process. A close observation of these powder particles shows their agglomeration, which can be due to the sintering of fine powder particles adjacent to the melt pool caused by the thermal effects of the L-PBF process (Figure 14(d)). The intensified sinterability of fine powder particles arises from their noticeably higher specific surface area relative to volume compared to the coarse powder system $[70,71]$.
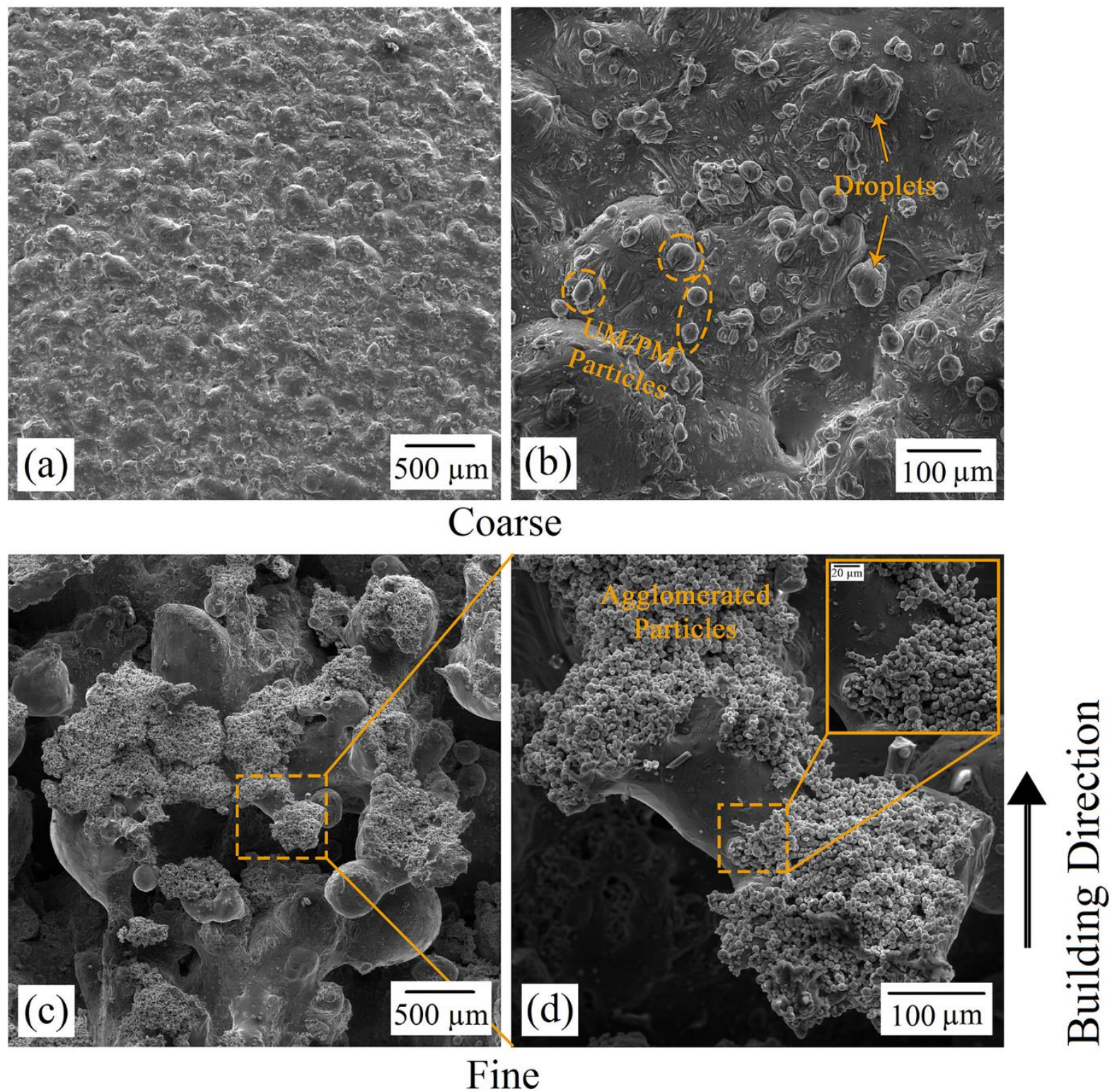

Figure 14. SEM micrographs of the side surface corresponding to parts obtained by L-PBF processing of: (a), (b) coarse and (c), (d) fine AlSilOMg powders using laser power of $335 \mathrm{~W}$, scanning speed of $1300 \mathrm{~mm} / \mathrm{s}$ and hatch spacing of $0.15 \mathrm{~mm}$. The higher magnification micrograph of the selected region in $(c)$ is provided in $(d)$. The inset in (d) shows the magnified view of powder particles adhered to the surface. UM/PM refers to un-melted/partially melted. 
The X-Y plane dimensional accuracy was also found to be a function of the hatch spacing. As shown in Figure 13(a), the hatch spacing of $0.19 \mathrm{~mm}$ led to lower deviations in the area than that $0.15 \mathrm{~mm}$. This is almost valid for both fine and coarse powders within the applied range of $P / v$ ratio. In general, the highest dimensional accuracy (the lowest deviation in the area) belongs to parts obtained by processing of the coarse powder with the hatch spacing of $0.19 \mathrm{~mm}$. However, for almost the whole range of $P / v$ ratio, L-PBF processing of the fine powder with the hatch spacing of $0.15 \mathrm{~mm}$ led to the worst dimensional accuracy in the X-Y plane. This may be attributed to the elevated heat input transferred to the surrounding powder media at lower hatch spacing. The dimensional accuracy measurement results suggest that the fabrication of sound parts with the fine powder feedstock is challenging not only from the densification level perspective but also from the dimensional accuracy viewpoint.

\subsubsection{Building direction (Z-direction)}

The dimensional accuracy along the $\mathrm{Z}$ direction (building direction) is shown in Figure 15 for the optimum samples of both the coarse and fine powder cases. The part obtained from the fine powder has a lower dimensional accuracy (higher percentage of deviation from the nominal height).

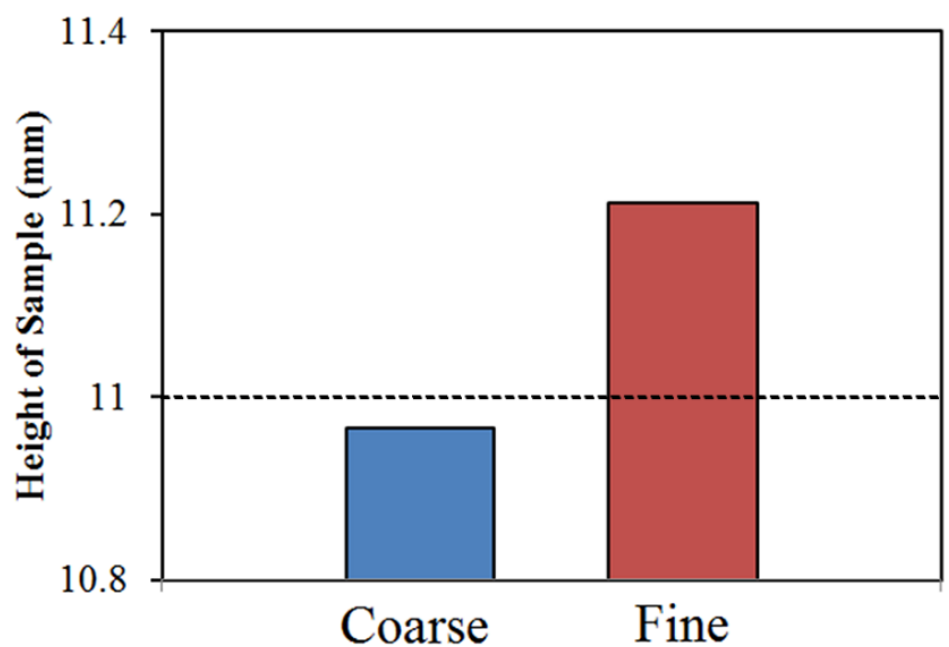

Figure 15. The deviation from the nominal height of samples with the optimum density obtained by L-PBF processing of coarse $\left(\boldsymbol{P}=335 \mathrm{~W}, \boldsymbol{v}=1050 \mathrm{~mm} / \mathrm{s}, \boldsymbol{h}=0.15 \mathrm{~mm}\right.$ and $\left.\boldsymbol{E}_{V}=21.9 \mathrm{~J} / \mathrm{mm} 3\right)$ and fine $(\boldsymbol{P}=335 \mathrm{~W}, \boldsymbol{v}=1050$ $\mathrm{mm} / \mathrm{s}, \boldsymbol{h}=0.15 \mathrm{~mm}$ and $\left.\boldsymbol{E}_{\boldsymbol{V}}=16.3 \mathrm{~J} / \mathrm{mm} 3\right)$ AlSilOMg powders. The nominal height refers to the height of samples after being cut off the build plate. The errors associated with measurements are 4.3 and $6.5 \mu \mathrm{m}$ for coarse and fine powder cases, respectively.

This can be justified based on the higher cohesive forces existing among the particles of the fine powder system compared to the coarse one [16]. As mentioned before, the decrease in the size of powder particles is accompanied by an increase in the specific surface area relative to volume and, consequently, the interparticle cohesive forces (e.g., van der Waals and electrostatic forces). Therefore, the fine powder system has a high tendency to form particle clusters to reduce the surface energy. Depending on their size, these 
agglomerates adversely affect the uniformity of the powder bed during the powder deposition stage through two different scenarios. If the agglomerates are larger than $\boldsymbol{t}_{\boldsymbol{e f f}}$, they not only fail to settle on the substrate but also sweep the powder particles ahead of them, leading to the decreased overall powder bed packing density and uneven powder bed [55]. The clusters smaller than $\boldsymbol{t}_{\boldsymbol{e f f}}$ might be able to settle on the substrate. However, the size and population of particles deposited ahead, behind and on top of these agglomerates are completely different, resulting in local non-uniformities in the powder bed. Each of these two scenarios leads to the formation of wavy surfaces in most of the parts obtained by L-PBF processing of fine powder feedstock (Figure 10(d) and (f), Figure 11(d) and (f), Figure 16(b)). Besides, the higher inter-particle friction in the fine powder system causes a poor powder flowability (higher SE provided in Table 4), which further decreases the dimensional accuracy in the $\mathrm{Z}$ direction. Lower flowability is believed to reduce the overall thickness of the powder bed and result in the deviation from the nominal height of the coupons [59]. As it is evident in Figure 16, the height of the part fabricated by the fine powder is lower than that of the coarse one, which is directly attributed to the poor flow behavior of the fine powder. It is of note that the higher volume fraction of defects in coupons fabricated by the fine powder system is another factor adversely affecting the dimensional accuracy in the $\mathrm{Z}$ direction (Figure 16). The defects formed in each layer influence not only the layer in which they are located but also the subsequent layer(s). In other words, the formation of a non-uniform consolidated layer jeopardizes the uniformity of the powder layer deposited on top of it and in turn hinders the creation of subsequent uniform layers.
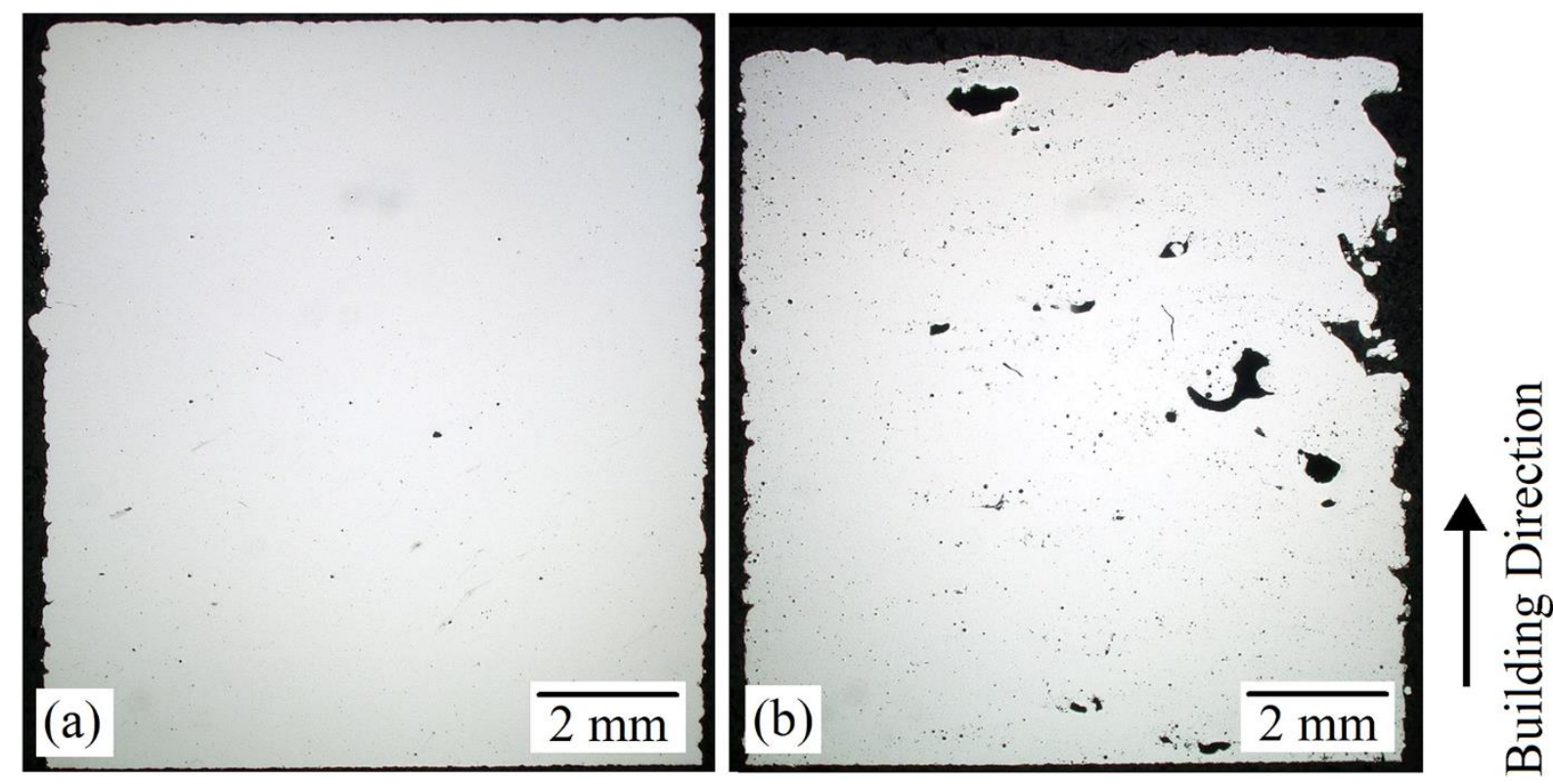

Figure 16. Cross-sectional optical micrographs of parts manufactured by L-PBF processing of: (a) coarse and (b) fine AlSilOMg powders using laser power of $370 \mathrm{~W}$, scanning speed of $1300 \mathrm{~mm} / \mathrm{s}$ and hatch spacing of $0.19 \mathrm{~mm}$. 


\subsection{Microstructural characterization}

Figure 17 presents optical micrographs of the cross-sections for parts fabricated by L-PBF processing of coarse and fine powders using the same $E_{V}$. As being observed, cross-sections of the successive melt pools represent the layer-wise nature of the process. The typical semi-elliptical shape of the melt pool is evident in macrostructures due to the employed scanning strategy. The microstructures of parts processed by fine and coarse powders seem to show no considerable difference in the size of melt pools. Higher magnification micrographs provided in Figure 17(b) and (d) reveal the difference between the microstructure of the melt pool interiors and boundaries. This is why the melt pools can be observed in the L-PBF processed AlSi10Mg components.
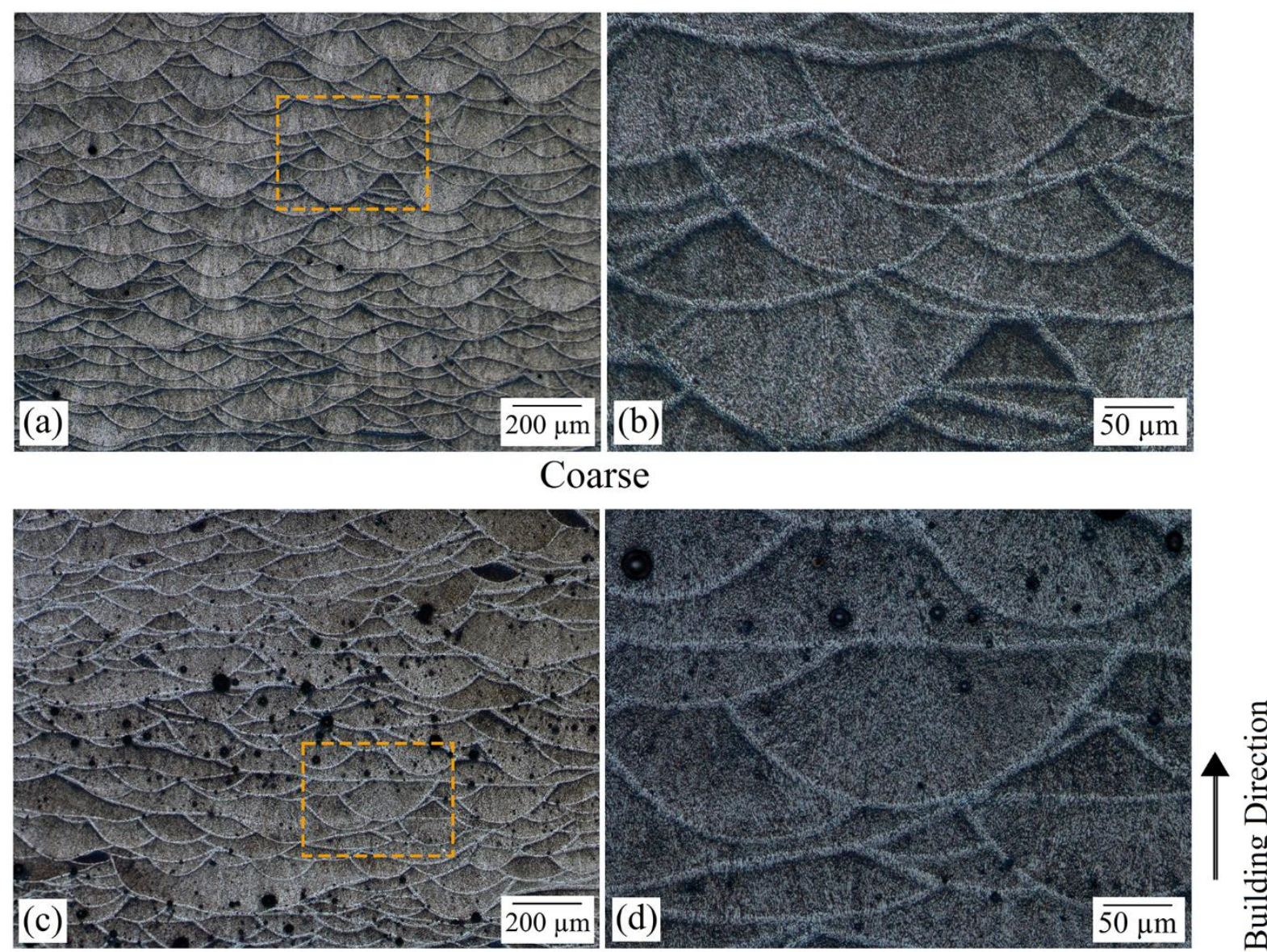

Fine

Figure 17. Cross-sectional optical micrographs of parts fabricated by L-PBF processing of: (a), (b) coarse $\left(\boldsymbol{E}_{V}=21.9 \mathrm{~J} / \mathrm{mm} 3\right)$ and $(\mathrm{c})$, (d) fine $\left(\boldsymbol{E}_{V}=16.3 \mathrm{~J} / \mathrm{mm} 3\right)$ AlSilOMg powders using laser powder of $335 \mathrm{~W}$, scanning speed of $1050 \mathrm{~mm} / \mathrm{s}$ and hatch spacing of $0.15 \mathrm{~mm}$. (b) and (d) are higher magnification micrographs of boxed regions in (a) and (c), respectively.

To have a better understanding of the microstructural evolutions, SEM micrographs of the same samples provided in Figure 17 are shown in Figure 18. The microstructures presented in Figure 18(a) and (b) reveal 
a band structure of alternating coarse and fine structures in parts manufactured by either the fine or the coarse powder. Detailed microstructures of different regions presented in Figure 18(a) and (b) show that the obtained inhomogeneous microstructures can be divided into three distinct regions having different microstructural features; the core of melt pools with a fine microstructure (MP-fine), the boundary of melt pools with a coarse microstructure (MP-coarse) and the heat-affected zone (HAZ). Moving from layer $n$ to layer $n+1$ along the boundary, HAZ, MP-coarse and MP-fine regions are distinguishable. The HAZ is defined as the region in which the previous track/layer (layer $n$ ) experiences the thermal effects of the next track/layer (layer $n+1$ ) and may undergo microstructural changes. To analyze the microstructures developed inside the melt pools, the mode of solidification needs to be examined. The solidification mode of the melt pool is governed by the $G / R$ ratio, in which $G$ and $R$ are the thermal gradient and solidification rate, respectively [72]. The micrographs shown in Figure 18 reveal the formation of a micro-cellular microstructure, in which fine $\alpha$-Al cells are decorated by Si particles segregated at the cell boundaries. However, the size of cells varies from the boundary toward the center of the melt pool due to the variations in the $G \times R$, which governs the microstructural refinement $[59,72]$. The finer microstructure of the MPfine than the MP-coarse can be attributed to the higher $G \times R$ values induced in the center of the melt pool. The cellular microstructure also seems to be oriented mainly along the center of the melt pool. This directionality is known to be due the unidirectional heat flux occurring from center toward the boundaries of the melt pool in the welding and AM $[59,73,74]$. Such a thermal gradient allows preferential growth ( $<100>$ direction in metals with cubic crystal structure such as Al) opposite to the heat flux vector, leading to the directional solidification [75-78].

The comparison of the melt pool interior microstructures (MP-fine) revealed a coarser microstructure (larger cells) for the sample obtained by L-PBF processing of the fine powder (Figure 18(c) and (d)). Based on the measurements performed on both powder cases using ImageJ Software, the cell size of the MP-F region was $1.04 \pm 0.12$ and $0.66 \pm 0.14$ for fine and coarse powder cases, respectively. This shows that the cell size of the part fabricated by the fine powder is $57 \%$ larger than that obtained by the coarse powder, suggesting a significant difference between their microstructural features. This can be ascribed to the higher laser absorptivity of the fine powder, which may act to elevate the melt pool temperature or reduce the cooling rate (Figure 5). 

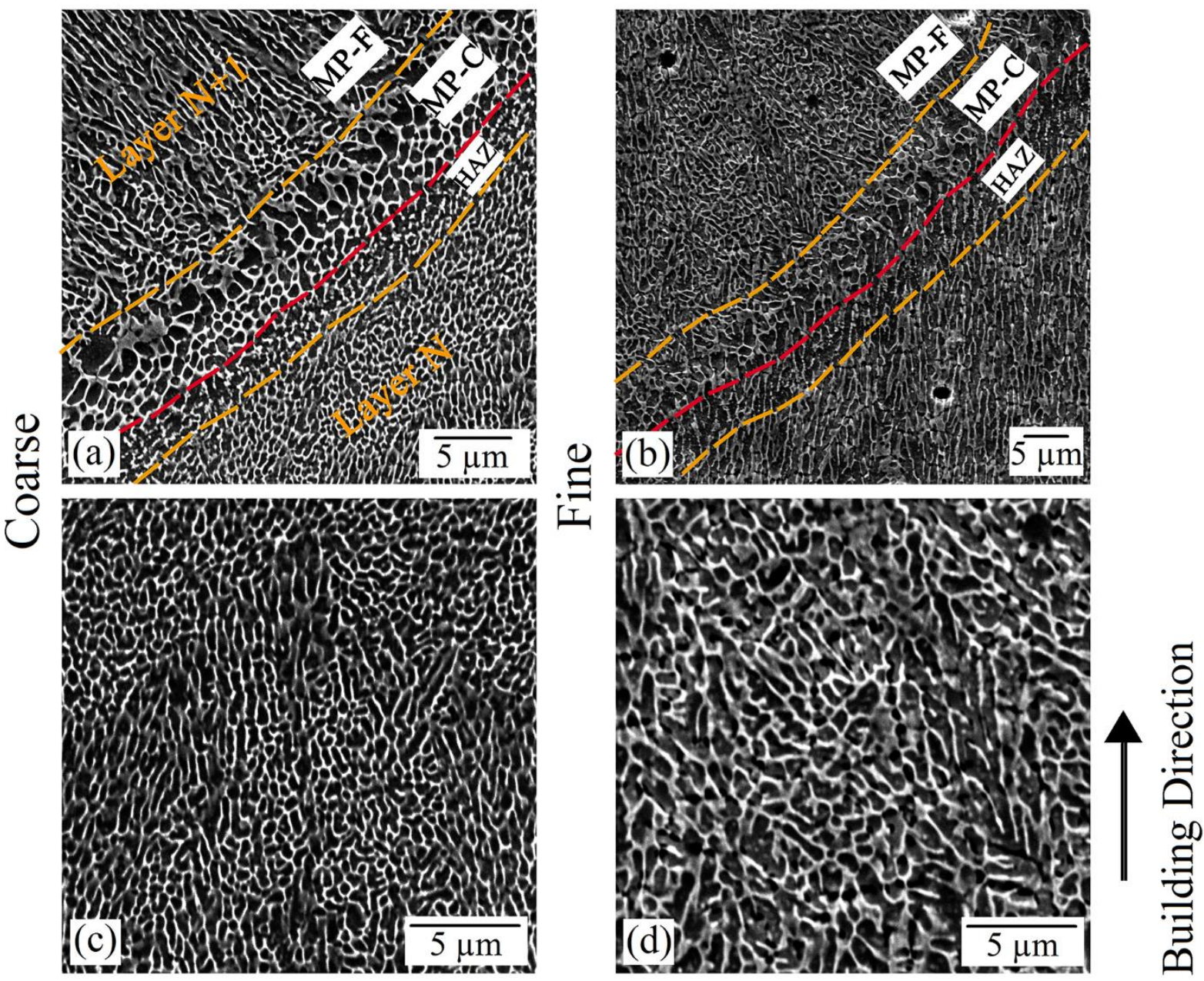

Figure 18. SEM microstructure for parts obtained by L-PBF processing of: $($ a $)$, (c) coarse $\left(\boldsymbol{E}_{V}=21.9 \mathrm{~J} / \mathrm{mm} 3\right)$ and (b), (d) fine $\left(\boldsymbol{E}_{\boldsymbol{V}}=16.3 \mathrm{~J} / \mathrm{mm} 3\right)$ AlSilOMg powders using laser powder of $335 \mathrm{~W}$, scanning speed of $1050 \mathrm{~mm} / \mathrm{s}$ and hatch spacing of $0.15 \mathrm{~mm}$. (a) and (b) show the variation in the microstructure adjacent to the melt pool boundaries. $(c)$ and $(d)$ are enclosed views of the $M P-F$ regions shown in $(a)$ and $(b)$, respectively. $M P-F, M P-C$ and $H A Z$ refer to the melt pool-fine, melt pool-coarse, and heat-affected zone, respectively.

A close observation of the obtained microstructures unveils the existence of micro-cracks randomly distributed in the part fabricated by L-PBF processing of the fine powder (Figure 19(b), (c)). These microcracks were found throughout the part and seemed to be inter-connected. The formation of these cracks may be attributed to the higher oxygen content of the fine powder system, which paves the way for the formation of $\mathrm{Al}$ oxide with poor wettability by the $\mathrm{Al}$ melt during L-PBF processing. Despite the case of the fine powder, the part achieved by the coarse powder was almost free from these cracks (Figure 19(a)). 

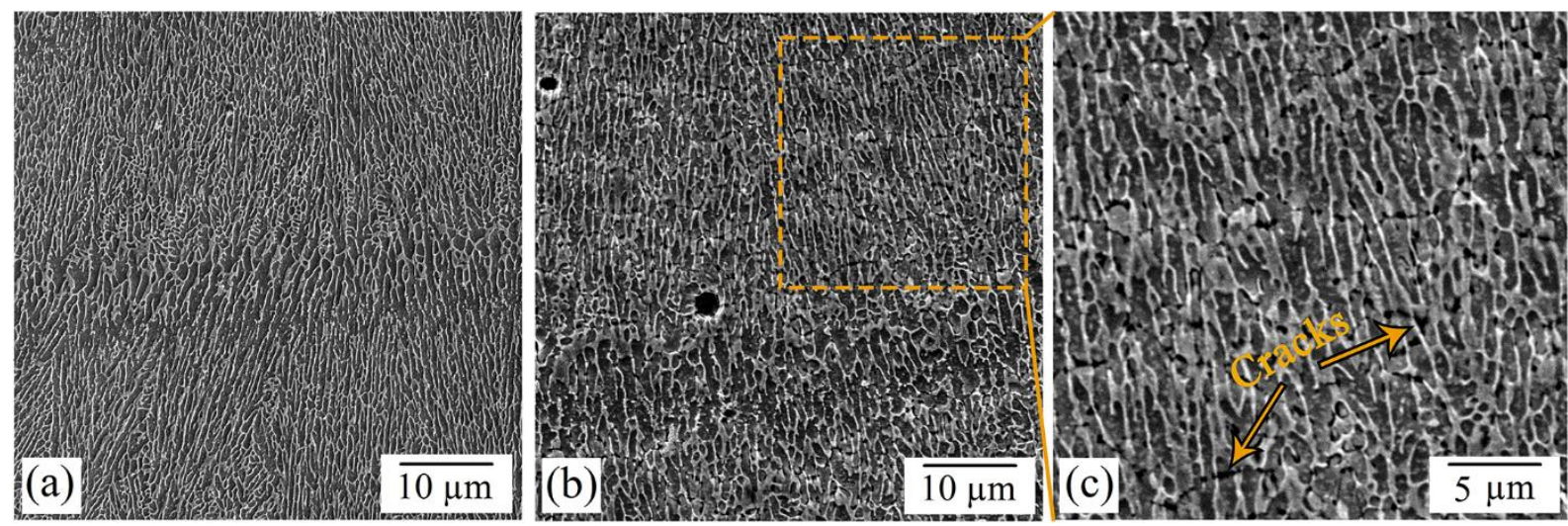

Figure 19. Typical SEM micrographs of parts achieved by L-PBF processing of: (a) coarse; and (b), (c) fine AlSilOMg powders using laser powder of $335 \mathrm{~W}$, scanning speed of $1050 \mathrm{~mm} / \mathrm{s}$ and hatch spacing of $0.15 \mathrm{~mm}\left(\boldsymbol{E}_{V}=\right.$ $16.3 \mathrm{~J} / \mathrm{mm} 3)$. (c) Enclosed view of micro-cracks existing in (b).

\subsection{Microhardness}

Microhardness measurement results are depicted in Figure 20 as a function of the $P / v$ ratio and hatch spacing for both fine and coarse powder cases. The obtained microhardness data showed high accuracy and repeatability, with the maximum coefficient of variation less than $5 \%$ for both fine and coarse powder cases. It can be inferred that regardless of the $P / v$ value and the employed hatch spacing, the coarse powder resulted in higher microhardness compared to the fine powder. The average microhardness of the samples fabricated by the coarse powder system is 3-15.5 HV higher than those for the fine powder feedstock, depending on the process parameters. This higher hardness can be traced back to two factors:

I. Finer microstructure: As shown in Figure 18, the finer cellular microstructure in the case of the coarse powder can more efficiently resist the plastic deformation and consequently lead to the higher hardness and strength [79].

II. Lower amount of micro-cracks: The micro-cracks existing in the part fabricated from the fine powder (Figure 19(b), (c)) can cause an easier collapse of the material underneath the indenter during the microhardness loading. Unlike the macro-hardness test, the microhardness measurement is not influenced by the porosities existing within the L-PBF processed parts since locally defectfree areas are typically selected by microstructural observations for indentation. Moreover, the indentation depth of the microhardness test is believed to be small enough to avoid any interactions with the sub-surface pores $[10,80]$. However, the size of micro-cracks observed in the case of fine powder is considerably smaller than the indentation size, meaning that these cracks can play a role in decreasing the microhardness.

It is worth noting that for both the coarse and fine powder cases, the microhardness follows a decreasing trend when increasing the $P / v$ ratio. Moreover, the results also reveal that for both powders, the hatch spacing of $0.15 \mathrm{~mm}$ leads to lower microhardness than that of $0.19 \mathrm{~mm}$. Both of these findings can be 
ascribed to the microstructural coarsening caused by the elevated heat induced in the system by either increase in $P / v$ ratio or decrease in the hatch spacing (Eq. 6). The coarser microstructure (larger cell size) associated with the lower cooling rate results in decreased hardness, as suggested by the well-known HallPetch equation. In other words, due to the significant role of grain boundaries on the movement of dislocations, the decreased fraction of cell boundaries obtained by the microstructure coarsening reduces the plastic deformation resistivity and consequently lowers the hardness of the material [81].

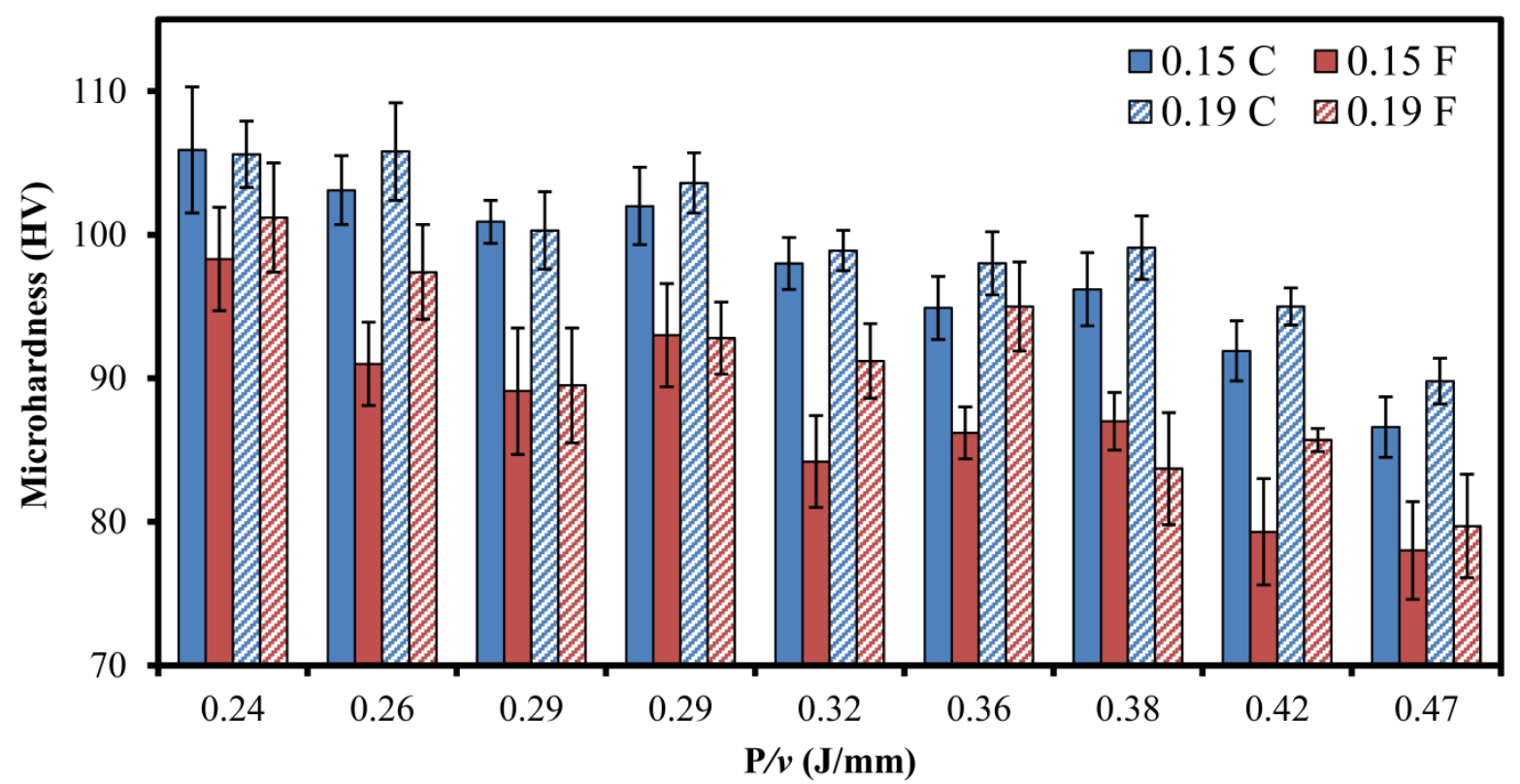

Figure 20. The variation in the microhardness of parts achieved by L-PBF processing of fine $(F)$ and coarse $(C)$ AlSilOMg powders as a function of the employed $\boldsymbol{P} / \boldsymbol{v}$ ratio for two different hatch spacings of 0.15 and $0.19 \mathrm{~mm}$.

\section{Conclusions}

This study was aimed at investigating the role of powder particle size on the L-PBF processability of the AlSi10Mg alloy. For this purpose, two different powders with the mean particle sizes of $9 \mu \mathrm{m}$ (fine) and $40 \mu \mathrm{m}$ (coarse) were subjected to the L-PBF process to fabricate parts using various laser powders, scanning speeds and hatch spacings. A modified volumetric energy density was introduced to compare the parts, which takes the effects of the laser absorptivity and the effective powder layer thickness also into account. The influence of process parameters on the densification level, top and side surface integrity, dimensional accuracy, microstructural evolutions and microhardness was explored, and the parts obtained by L-PBF processing of the fine and coarse powders were compared. The main findings can be summarized as follows:

1. The flowability and packing density of the fine powder was $75 \%$ and $\sim 30 \%$ lower than the coarse powder, respectively. 
2. For both powders, the part density first raised and then declined by increasing the energy density. Within the applied range of energy density, inferior densification levels were achieved in the case of fine powder due to its lower powder bed packing density, higher oxygen content and higher effective powder layer thickness.

3. The maximum part densities were $\sim 95$ and $\sim 99$ for the fine and coarse powder cases, respectively.

4. The coarse powder led to a lower top surface roughness compared to the fine powder. Depending on the scanning speed, a difference of $5-73 \%$ between the $S_{a}$ of parts obtained by the fine and coarse powder cases was attained.

5. The fine powder feedstock led to the lower dimensional accuracy in the X-Y plane, mainly due to the adherence of a noticeable volume of un-melted/partially melted powder particles to the side surfaces.

6. Due to its noticeably lower flowability and great tendency to form agglomerates, the parts fabricated by the fine powder had lower dimensional accuracy along the building direction (height).

7. The coarse powder resulted in finer cellular structure and, consequently, higher microhardness than the fine powder feedstock. 


\section{References}

[1] P.K. Schelling, L. Shi, K.E. Goodson, Managing heat for electronics, Materials Today 8(6) (2005) 3035 .

[2] S.C. Tjong, Recent progress in the development and properties of novel metal matrix nanocomposites reinforced with carbon nanotubes and graphene nanosheets, Materials Science and Engineering: R: Reports 74(10) (2013) 281-350.

[3] K.J. Maloney, K.D. Fink, T.A. Schaedler, J.A. Kolodziejska, A.J. Jacobsen, C.S. Roper, Multifunctional heat exchangers derived from three-dimensional micro-lattice structures, International Journal of Heat and Mass Transfer 55(9-10) (2012) 2486-2493.

[4] H.N. Wadley, D.T. Queheillalt, Thermal applications of cellular lattice structures, Materials science forum, Trans Tech Publ, 2007, pp. 242-247.

[5] D. Jafari, W.W. Wits, The utilization of selective laser melting technology on heat transfer devices for thermal energy conversion applications: A review, Renewable and Sustainable Energy Reviews 91 (2018) 420-442.

[6] E. Fereiduni, A. Ghasemi, M. Elbestawi, Selective Laser Melting of Aluminum and Titanium Matrix Composites: Recent Progress and Potential Applications in the Aerospace Industry, Aerospace 7(6) (2020) 77.

[7] M. Balbaa, S. Mekhiel, M. Elbestawi, J. McIsaac, On selective laser melting of Inconel 718:

Densification, surface roughness, and residual stresses, Materials \& Design (2020) 108818.

[8] E. Louvis, P. Fox, C.J. Sutcliffe, Selective laser melting of aluminium components, Journal of Materials Processing Technology 211(2) (2011) 275-284.

[9] E. Brandl, U. Heckenberger, V. Holzinger, D. Buchbinder, Additive manufactured AlSi10Mg samples using Selective Laser Melting (SLM): Microstructure, high cycle fatigue, and fracture behavior, Materials \& Design 34 (2012) 159-169.

[10] E. Fereiduni, A. Ghasemi, M. Elbestawi, Selective laser melting of hybrid ex-situ/in-situ reinforced titanium matrix composites: Laser/powder interaction, reinforcement formation mechanism, and nonequilibrium microstructural evolutions, Materials \& Design 184 (2019) 108185.

[11] J.K. Tiwari, A. Mandal, N. Sathish, A.K. Agrawal, A.K. Srivastava, Investigation of porosity, microstructure and mechanical properties of additively manufactured graphene reinforced $\mathrm{AlSi} 10 \mathrm{Mg}$ composite, Additive Manufacturing 33 (2020) 101095.

[12] I. Astm, ASTM52900-15 Standard Terminology for Additive Manufacturing-General PrinciplesTerminology, ASTM International, West Conshohocken, PA 3(4) (2015) 5. 
[13] S.L. Sing, S. Huang, W.Y. Yeong, Effect of solution heat treatment on microstructure and mechanical properties of laser powder bed fusion produced cobalt-28chromium-6molybdenum, Materials Science and Engineering: A 769 (2020) 138511.

[14] A. Salmi, E. Atzeni, Residual stress analysis of thin AlSi10Mg parts produced by Laser Powder Bed Fusion, Virtual and Physical Prototyping 15(1) (2020) 49-61.

[15] D. Tiberto, U.E. Klotz, F. Held, G. Wolf, Additive manufacturing of copper alloys: influence of process parameters and alloying elements, Materials Science and Technology 35(8) (2019) 969-977. [16] J.H. Tan, W.L.E. Wong, K.W. Dalgarno, An overview of powder granulometry on feedstock and part performance in the selective laser melting process, Additive Manufacturing 18 (2017) 228-255.

[17] A. Simchi, The role of particle size on the laser sintering of iron powder, Metallurgical and Materials Transactions B 35(5) (2004) 937-948.

[18] H. Niu, I.H. CHANG, Selective laser sintering of gas and water atomized high speed steel powders, Scripta Materialia 41(1) (1999) 25-30.

[19] N.T. Aboulkhair, N.M. Everitt, I. Ashcroft, C. Tuck, Reducing porosity in AlSi10Mg parts processed by selective laser melting, Additive Manufacturing 1 (2014) 77-86.

[20] Standard Test Method for Minimum Ignition Energy of a Dust Cloud in Air.

[21] W.D. Sheridan, Reference Data Sheet for Aluminum, Meridian Engineering and Technology1996.

[22] C. Kuo, C. Chua, P. Peng, Y. Chen, S. Sing, S. Huang, Y. Su, Microstructure evolution and mechanical property response via 3D printing parameter development of $\mathrm{Al}-\mathrm{Sc}$ alloy, Virtual and Physical Prototyping 15(1) (2020) 120-129.

[23] W. Yu, S.L. Sing, C.K. Chua, X. Tian, Influence of re-melting on surface roughness and porosity of AlSi10Mg parts fabricated by selective laser melting, Journal of Alloys and Compounds 792 (2019) 574581.

[24] N.T. Aboulkhair, M. Simonelli, L. Parry, I. Ashcroft, C. Tuck, R. Hague, 3D printing of Aluminium alloys: Additive Manufacturing of Aluminium alloys using selective laser melting, Progress in Materials Science 106 (2019) 100578.

[25] M. Tang, P.C. Pistorius, Oxides , porosity and fatigue performance of AlSi10Mg parts produced by selective laser melting, International Journal of Fatigue 94 (2017) 192-201.

[26] E. Beevers, A.D. Brandão, J. Gumpinger, M. Gschweitl, C. Seyfert, P. Hofbauer, T. Rohr, T. Ghidini, Fatigue properties and material characteristics of additively manufactured AlSi10Mg-Effect of the contour parameter on the microstructure, density, residual stress, roughness and mechanical properties, International Journal of Fatigue 117 (2018) 148-162. 
[27] J.A. Muñiz-Lerma, A. Nommeots-Nomm, K.E. Waters, M. Brochu, A Comprehensive Approach to Powder Feedstock Characterization for Powder Bed Fusion Additive Manufacturing: A Case Study on AlSi7Mg, Materials 11(12) (2018) 2386.

[28] A.B. Spierings, M. Voegtlin, T. Bauer, K. Wegener, Powder flowability characterisation methodology for powder-bed-based metal additive manufacturing, Progress in Additive Manufacturing 1(1-2) (2016) 9-20.

[29] E. Fereiduni, A. Ghasemi, M. Elbestawi, Characterization of Composite Powder Feedstock from Powder Bed Fusion Additive Manufacturing Perspective, Materials 12(22) (2019) 3673.

[30] N. Karapatis, G. Egger, P. Gygax, R. Glardon, Optimization of powder layer density in selective laser sintering, 1999 International Solid Freeform Fabrication Symposium, 1999.

[31] A.B. Spierings, G. Levy, Comparison of density of stainless steel 316L parts produced with selective laser melting using different powder grades, Proceedings of the Annual International Solid Freeform Fabrication Symposium, Austin, TX, 2009, pp. 342-353.

[32] D. Bourell, B. Stucker, A. Spierings, N. Herres, G. Levy, Influence of the particle size distribution on surface quality and mechanical properties in AM steel parts, Rapid Prototyping Journal (2011).

[33] A.M. Elliott, P. Nandwana, D.H. Siddel, B. Compton, A method for measuring powder bed density in binder jet additive manufacturing process and the powder feedstock characteristics influencing the powder bed density, Oak Ridge National Lab.(ORNL), Oak Ridge, TN (United States). High ..., 2016. [34] Y. Sun, S. Gulizia, C. Oh, C. Doblin, Y. Yang, M. Qian, Manipulation and characterization of a novel titanium powder precursor for additive manufacturing applications, Jom 67(3) (2015) 564-572. [35] Standard Test Method for Particle Size Distribution of Metal Powders and Related Compounds by Light Scattering, ASTM B822-10, ASTM International, West Conshohocken, PA, 2010.

[36] S. Özbilen, Satellite formation mechanism in gas atomised powders, Powder metallurgy 42(1) (1999) 70-78.

[37] Standard Test Methods for Flow Rate of Metal Powders Using the Hall Flowmeter Funnel, ASTM B213-17, ASTM International, West Conshohocken, PA, 2017.

[38] D. van der Wiel, ADVANCED POWDER CHARACTERIZATION FOR ADDITIVE MANUFACTURING, ADVANCED MATERIALS \& PROCESSES 177(5) (2019) 22-26.

[39] L.I. Escano, N.D. Parab, L. Xiong, Q. Guo, C. Zhao, K. Fezzaa, W. Everhart, T. Sun, L. Chen, Revealing particle-scale powder spreading dynamics in powder-bed-based additive manufacturing process by high-speed x-ray imaging, Scientific reports 8(1) (2018) 1-11.

[40] H. Chen, Q. Wei, S. Wen, Z. Li, Y. Shi, Flow behavior of powder particles in layering process of selective laser melting: Numerical modeling and experimental verification based on discrete element method, International Journal of Machine Tools and Manufacture 123 (2017) 146-159. 
[41] H. Chen, Y. Chen, Y. Liu, Q. Wei, Y. Shi, W. Yan, Packing quality of powder layer during counterrolling-type powder spreading process in additive manufacturing, International Journal of Machine Tools and Manufacture (2020) 103553.

[42] H. Chen, Q. Wei, Y. Zhang, F. Chen, Y. Shi, W. Yan, Powder-spreading mechanisms in powderbed-based additive manufacturing: Experiments and computational modeling, Acta Materialia 179 (2019) 158-171.

[43] M. Ahmed, M. Pasha, W. Nan, M. Ghadiri, A simple method for assessing powder spreadability for additive manufacturing, Powder Technology (2020).

[44] Renishaw, Meander stripe and chessboard hatchings pattern.

https://resources.renishaw.com/en/details/--95492. (Accessed July 7 2020).

[45] Standard Test Methods for Density of Compacted or Sintered Powder Metallurgy (PM) Products Using Archimedes' Principle, ASTM B962-17, ASTM International, West Conshohocken, PA, 2017.

[46] C. Yan, L. Hao, A. Hussein, P. Young, J. Huang, W. Zhu, Microstructure and mechanical properties of aluminium alloy cellular lattice structures manufactured by direct metal laser sintering, Materials Science and Engineering: A 628 (2015) 238-246.

[47] K. Kempen, L. Thijs, J. Van Humbeeck, J.-P. Kruth, Mechanical properties of AlSi10Mg produced by selective laser melting, Physics Procedia 39 (2012) 439-446.

[48] M. Leturia, M. Benali, S. Lagarde, I. Ronga, K. Saleh, Characterization of flow properties of cohesive powders: A comparative study of traditional and new testing methods, Powder technology 253 (2014) 406-423.

[49] L.J. Jallo, Y. Chen, J. Bowen, F. Etzler, R. Dave, Prediction of inter-particle adhesion force from surface energy and surface roughness, Journal of Adhesion Science and Technology 25(4-5) (2011) 367384.

[50] S. Dadbakhsh, L. Verbelen, T. Vandeputte, D. Strobbe, P. Van Puyvelde, J.-P. Kruth, Effect of powder size and shape on the SLS processability and mechanical properties of a TPU elastomer, Physics Procedia 83 (2016) 971-980.

[51] X. Li, G. Ji, Z. Chen, A. Addad, Y. Wu, H. Wang, J. Vleugels, J. Van Humbeeck, J.-P. Kruth, Selective laser melting of nano-TiB 2 decorated AlSi10Mg alloy with high fracture strength and ductility, Acta Materialia 129 (2017) 183-193.

[52] C. Boley, S.A. Khairallah, A.M. Rubenchik, Calculation of laser absorption by metal powders in additive manufacturing, Applied optics 54(9) (2015) 2477-2482.

[53] A. Rubenchik, S. Wu, S. Mitchell, I. Golosker, M. LeBlanc, N. Peterson, Direct measurements of temperature-dependent laser absorptivity of metal powders, Applied optics 54(24) (2015) 7230-7233. 
[54] L. Thijs, F. Verhaeghe, T. Craeghs, J. Van Humbeeck, J.-P. Kruth, A study of the microstructural evolution during selective laser melting of Ti-6Al-4V, Acta Materialia 58(9) (2010) 3303-3312.

[55] H. Mindt, M. Megahed, N. Lavery, M. Holmes, S. Brown, Powder Bed Layer Characteristics: The Overseen First-Order Process Input, Metallurgical and Materials Transactions A 47(8) (2016) 3811-3822. [56] C. Panwisawas, C. Qiu, Y. Sovani, J. Brooks, M. Attallah, H. Basoalto, On the role of thermal fluid dynamics into the evolution of porosity during selective laser melting, Scripta Materialia 105 (2015) 1417.

[57] L. Cordova, T. Bor, M. de Smit, M. Campos, T. Tinga, Measuring the spreadability of pre-treated and moisturized powders for laser powder bed fusion, Additive Manufacturing 32 (2020) 101082.

[58] D. Gu, M. Xia, D. Dai, On the role of powder flow behavior in fluid thermodynamics and laser processability of Ni-based composites by selective laser melting, International Journal of Machine Tools and Manufacture 137 (2019) 67-78.

[59] T. DebRoy, H. Wei, J. Zuback, T. Mukherjee, J. Elmer, J. Milewski, A.M. Beese, A. Wilson-Heid, A. De, W. Zhang, Additive manufacturing of metallic components-process, structure and properties, Progress in Materials Science 92 (2018) 112-224.

[60] E. Fereiduni, M. Elbestawi, Process-structure-property relationships in additively manufactured metal matrix composites, Additive Manufacturing of Emerging Materials, Springer2019, pp. 111-177. [61] E. Fereiduni, M. Yakout, M. Elbestawi, Laser-based additive manufacturing of lightweight metal matrix composites, Additive Manufacturing of Emerging Materials, Springer2019, pp. 55-109.

[62] S. Lowell, J.E. Shields, M.A. Thomas, M. Thommes, Characterization of porous solids and powders: surface area, pore size and density, Springer Science \& Business Media2012.

[63] A.H. Maamoun, M. Elbestawi, G.K. Dosbaeva, S.C. Veldhuis, Thermal post-processing of AlSi10Mg parts produced by Selective Laser Melting using recycled powder, Additive Manufacturing 21 (2018) 234-247.

[64] A.B. Spierings, N. Herres, G. Levy, Influence of the particle size distribution on surface quality and mechanical properties in AM steel parts, Rapid Prototyping Journal 17(3) (2011) 195-202.

[65] B. Liu, R. Wildman, C. Tuck, I. Ashcroft, R. Hague, Investigation the effect of particle size distribution on processing parameters optimisation in selective laser melting process, Additive manufacturing research group, Loughborough University (2011) 227-238.

[66] M. Rombouts, J.-P. Kruth, L. Froyen, P. Mercelis, Fundamentals of selective laser melting of alloyed steel powders, CIRP Annals-Manufacturing Technology 55(1) (2006) 187-192.

[67] P. Bidare, I. Bitharas, R. Ward, M. Attallah, A.J. Moore, Fluid and particle dynamics in laser powder bed fusion, Acta Materialia 142 (2018) 107-120. 
[68] H. Chen, W. Yan, Spattering and denudation in laser powder bed fusion process: Multiphase flow modelling, Acta Materialia 196 (2020) 154-167.

[69] C. Galy, E. Le Guen, E. Lacoste, C. Arvieu, Main defects observed in aluminum alloy parts produced by SLM: From causes to consequences, Additive Manufacturing 22 (2018) 165-175.

[70] O. Ertugrul, H.-S. Park, K. Onel, M. Willert-Porada, Effect of particle size and heating rate in microwave sintering of 316L stainless steel, Powder technology 253 (2014) 703-709.

[71] J. Lu, Z. Lu, C. Peng, X. Li, H. Jiang, Influence of particle size on sinterability, crystallisation kinetics and flexural strength of wollastonite glass-ceramics from waste glass and fly ash, Materials Chemistry and Physics 148(1-2) (2014) 449-456.

[72] S. Kou, Welding metallurgy, New Jersey, USA (2003) 431-446.

[73] T. Lienert, T. Siewert, S. Babu, V. Acoff, Fundamentals of Weld Solidification, (2011).

[74] Z. Xiong, S. Liu, S. Li, Y. Shi, Y. Yang, R. Misra, Role of melt pool boundary condition in determining the mechanical properties of selective laser melting AlSi10Mg alloy, Materials Science and Engineering: A 740 (2019) 148-156.

[75] M. Simonelli, Y.Y. Tse, C. Tuck, On the texture formation of selective laser melted Ti-6Al-4V, Metallurgical and materials transactions A 45(6) (2014) 2863-2872.

[76] S.M. Thompson, L. Bian, N. Shamsaei, A. Yadollahi, An overview of Direct Laser Deposition for additive manufacturing; Part I: Transport phenomena, modeling and diagnostics, Additive Manufacturing 8 (2015) 36-62.

[77] X. Liu, C. Zhao, X. Zhou, Z. Shen, W. Liu, Microstructure of selective laser melted AlSi10Mg alloy, Materials \& Design 168 (2019) 107677.

[78] S.D. Jadhav, S. Dadbakhsh, L. Goossens, J.P. Kruth, J. Van Humbeeck, K. Vanmeensel, Influence of selective laser melting process parameters on texture evolution in pure copper, Journal of Materials Processing Technology 270 (2019) 47-58.

[79] D.R. Askeland, P.P. Phulé, W.J. Wright, D. Bhattacharya, The science and engineering of materials, (2003).

[80] J. Zuback, T. DebRoy, The hardness of additively manufactured alloys, Materials 11(11) (2018) 2070.

[81] N. Hansen, Hall-Petch relation and boundary strengthening, Scripta Materialia 51(8) (2004) 801806. 